OPEN ACCESS

Edited by:

Johannes Boltze,

University of Warwick,

United Kingdom

Reviewed by:

Laura Säisänen,

Kuopio University Hospital, Finland

Mariagiovanna Cantone,

Sant'Elia Hospital, Italy

*Correspondence:

Wolnei Caumo

wcaumo@hcpa.edu.br

Specialty section:

This article was submitted to

Stroke,

a section of the journal

Frontiers in Neurology

Received: 10 March 2021

Accepted: 02 July 2021

Published: 18 August 2021

Citation:

Betancur DFA, Tarragó MdGL, Torres

ILS, Fregni F and Caumo W (2021)

Central Post-Stroke Pain: An

Integrative Review of Somatotopic

Damage, Clinical Symptoms, and

Neurophysiological Measures.

Front. Neurol. 12:678198.

doi: 10.3389/fneur.2021.678198

\section{Central Post-Stroke Pain: An Integrative Review of Somatotopic Damage, Clinical Symptoms, and Neurophysiological Measures}

\author{
Daniel Fernando Arias Betancur ${ }^{1,2}$, Maria da Graça Lopes Tarragó ${ }^{3}$, \\ Iraci Lucena da Silva Torres ${ }^{1,4}$, Felipe Fregni ${ }^{5}$ and Wolnei Caumo ${ }^{1,2,6,7 *}$ \\ ${ }^{1}$ Graduate Program in Medical Sciences, School of Medicine, Federal University of Rio Grande do Sul (UFRGS), Porto \\ Alegre, Brazil, ${ }^{2}$ Laboratory of Pain \& Neuromodulation, Clinical Research Center, Hospital de Clínicas de Porto Alegre \\ (HCPA), Porto Alegre, Brazil, ${ }^{3}$ Physical Medicine and Rehabilitation Service, Hospital de Clínicas de Porto Alegre (HCPA), \\ Porto Alegre, Brazil, ${ }^{4}$ Pharmacology of Pain and Neuromodulation: Pre-clinical Investigations Research Group, Federal \\ University of Rio Grande Do Sul (UFRGS), Porto Alegre, Brazil, ${ }^{5}$ Laboratory of Neuromodulation and Center for Clinical \\ Research Learning, Physics, and Rehabilitation Department, Spaulding Rehabilitation Hospital, Boston, MA, United States, \\ ${ }^{6}$ Pain and Palliative Care Service, Hospital de Clínicas de Porto Alegre (HCPA), Porto Alegre, Brazil, ${ }^{7}$ Department of Surgery, \\ School of Medicine, Federal University of Rio Grande Do Sul (UFRGS), Porto Alegre, Brazil
}

Introduction: The physiopathology of central post-stroke pain (CPSP) is poorly understood, which may contribute to the limitations of diagnostic and therapeutic advancements. Thus, the current systematic review was conducted to examine, from an integrated perspective, the cortical neurophysiological changes observed via transcranial magnetic stimulation (TMS), focusing on the structural damage, and clinical symptoms in patients with CPSP.

Methods: The literature review included the databases EMBASE, PubMed, and ScienceDirect using the following search terms by MeSH or Entree descriptors: [(“Cerebral Stroke”) AND ("Pain" OR "Transcranial Magnetic Stimulation") AND (“Transcranial Magnetic Stimulation”)] (through September 29, 2020). A total of 297 articles related to CPSP were identified. Of these, only four quantitatively recorded cortical measurements.

Results: We found four studies with different methodologies and results of the TMS measures. According to the National Institutes of Health $(\mathrm{NIH})$ guidelines, two studies had low methodological quality and the other two studies had satisfactory methodological quality. The four studies compared the motor threshold (MT) of the stroke-affected hemisphere with the unaffected hemisphere or with healthy controls. Two studies assessed other cortical excitability measures, such as cortical silent period (CSP), short-interval intracortical inhibition (SICI), and intracortical facilitation (ICF). The main limitations in the interpretation of the results were the heterogeneity in parameter measurements, unknown cortical excitability measures as potential prognostic markers, the lack of a control group without pain, and the absence of consistent and validated diagnosis criteria. 
Conclusion: Despite the limited number of studies that prevented us from conducting a meta-analysis, the dataset of this systematic review provides evidence to improve the understanding of CPSP physiopathology. Additionally, these studies support the construction of a framework for diagnosis and will help improve the methodological quality of future research in somatosensory sequelae following stroke. Furthermore, they offer a way to integrate dysfunctional neuroplasticity markers that are indirectly assessed by neurophysiological measures with their correlated clinical symptoms.

Keywords: stroke, neuropathic pain, TMS, cortical excitability, cerebellum

\section{INTRODUCTION}

Stroke is the second leading cause of death in the world $(1,2)$. Among those who survive, motor and somatosensory sequelae compromise the functional capacity and quality of life in many individuals (3-5). In general, one can define two types of pain after stroke: pain associated with peripheral mechanisms (e.g., musculoskeletal, spastic pain, headache, and shoulder pain) and neuropathic central post-stroke pain (CPSP) (6). Although, CPSP is one of the primary sequelae following stroke, there is a gap in understanding its pathophysiology and a diagnostic definition (7). Dejerine and Roussy (8) performed the first description of CPSP in 1906. They described the clinical-anatomical correlation of patients diagnosed with a thalamic stroke who presented a syndrome characterized by intense pain, changes in superficial and deep sensorial perception, mild hemiplegia, choreoathetoid movements, astereognosis, and hemiataxia. Initial studies have linked CPSP to stroke in the thalamus, specifically the pulvinar, the ventral posteromedial, and posterolateral nuclei $(9,10)$. However, later studies described CPSP in lesions located in the lateral medulla (11), lenticulo-capsular area (12), pons, and in cortical areas (insula and operculum) $(13,14)$.

Although, there has been enormous progress in stroke treatment in recent decades, the rehabilitation of those who survive a stroke remains a challenge, specifically the recovery of disability, and well-being. Among these sequelae is CPSP, which has been shown to be slightly improved by pharmacological treatments. There is limited literature concerning this neuropathic pain category, primarily focusing on diagnosis and treatment. Thus, a better understanding of the neuroplasticity process might help progress in this field. In this regard, there is an urgent need to conduct studies investigating markers with diagnostic and prognostic potential to assist in the treatment of CPSP. This systematic review aimed to gather data from the literature concerning the physiopathology of CPSP and to critically examine these data to assist in planning future studies that may be able to help in the neurorehabilitation and optimization of functional recovery in individuals affected by CPSP. Specifically, the current review explored, from an integrative perspective, the relationships of the anatomical areas, clinical symptoms, and the cortical excitability (CE) parameters indexed by transcranial magnetic stimulation (TMS) measures. The TMS measures included motor threshold (MT), motor evoked potential (MEP), short intracortical inhibition (SICI), intracortical facilitation (ICF), and cortical silent period (CSP).
From this dataset, we hope to offer additional information to advance this field of knowledge and open a new avenue for the treatment and rehabilitation of individuals affected by CPSP.

\section{PRINCIPAL CONCEPTS IN CPSP}

\section{Prevalence and Incidence}

It is estimated that the prevalence of CPSP ranges from 1 to $35 \%$ (15). This broad estimate is possibly due to variabilities in the definition of this pain category, the inclusion criteria, and the length of patients' evaluation post-stroke (16). For example, the prevalence of CPSP was 25\% in an earlier study that included 63 patients with vascular damage to the medulla's lateral part (11). In another study, the prevalence of CPSP was $1 \%$ in patients whose assessment was 16 months post-stroke (17). Regarding the incidence of CPSP, a study found that, in an initial sample size of 207 stroke patients, $8 \%$ developed symptoms compatible with central neuropathic pain during the first year after stroke (18). However, commencement of symptoms showed extensive variations among studies. Nasreddine and Saver (19) found that most patients began experiencing symptoms within the first 6 months. In contrast, another study found cases in which CPSP appeared up to 10 years after the event (20). According to these data, it is possible that the course of CPSP across time can be variable, with several reports of some patients experiencing symptoms for years or throughout their entire life (6).

\section{Signs and Clinical Symptoms}

CPSP can be continuous or intermittent, with pain described as burning, throbbing, pressure, or freezing $(16,21)$. According to Boivie's review (22), abnormalities in stimulus perception were defined as hyperesthesia, hyperalgesia, hypoesthesia, paresthesia, dysesthesia, allodynia, or hyperpathy and may be associated with temporal and spatial summation. Bashir et al. (23) diagnosed CPSP in six patients, with a primary pain description of a burning sensation in $62.5 \%$ of them, followed by sensation of electric shock in $25 \%$. Additionally, this study found as aggravating factors movement of the extremity, contact with heat/cold, and psychological stress. The predominant sensory abnormalities identified were tactile allodynia and hyperalgesia, both with a prevalence of $35.7 \%$. Other authors have also emphasized impairment in the perception of stimuli by needle prick, temperature, or touch, and the lower frequency in vibration perception and joint positioning (16). Typically, pain is restricted to the anatomical area with somatosensory abnormalities (14) 
and impairment of body segments, both proximal and distal, which are correlated with the anatomical location of the lesion within the central nervous system (CNS) $(20,24)$. In capsulelenticular lesions, there is a higher prevalence of pain in the lower limbs than in the face or upper limbs (12). In thalamic lesions, contralateral hemi-body manifestations are the most frequent (25). Conversely, in medullary injuries, the signs and symptoms depend on the location of damage, with distinct symptoms if the lesion is lateral or medial. In lateral lesions, facial impairment symptoms might be either ipsilateral or contralateral, associated with pain descriptors of either burning or cold. In medial lesions, the most commonly reported impairment is in the trunk and extremities, with descriptors such as numbness and/or tingling (26).

\section{An Integrative View on the Diagnosis of CPSP}

CPSP is considered a chronic pain condition that has mobilized clinicians and researchers to improve the diagnostic criteria. Thus, the International Association for the Study of Pain (IASP) Committee established a panel of experts with a particular interest in neuropathic pain (NeuPSIG) to review a neuropathic pain classification system created in 2008 (27). According to this committee's guidelines, neuropathic pain diagnosis should include the patient's clinical history of neurological damage, which must have somatotopy, signs, and symptoms with correspondent plausibility to the damage in the CNS. Additionally, confirmatory tests are needed to identify such damage in the somatosensory system (27).

As specified in the IASP Committee's criteria, CPSP is manifested contralateral to the affected hemisphere. If the lesion is located in the brainstem, the pain distribution may occur on the ipsilateral side of the face (27). The diagnosis should be guided by history and clinical evaluation, complemented with neuroimaging data to increase diagnostic accuracy (28). It has been demonstrated that sensory evaluation can serve as a predictor of the development of CPSP. Post-stroke dysesthesia, allodynia, or hyperalgesia is associated with a 4.6-fold increase in the probability of CPSP development in the first 6 months following a brain vascular event. Similarly, the presence of early pain, or dysesthesia, and a reduced or an absent sensation to needle stick or cold increase the probability of post-stroke neuropathic pain 8-fold (29).

Despite clinicians' and researchers' best efforts to systematize the diagnostic criteria, this category of neuropathic pain after stroke remains a challenge, primarily due to the heterogeneity of the clinical symptoms. Both Klit et al. (28) and Hansen et al. (30) have proposed diagnostic criteria used to assess patients with CPSP. These criteria are presented in Table $\mathbf{1 .}$

\section{Physiopathology Theories and Plasticity Role in CPSP}

The pain pathway comprises a complex network of axonal projections to different brain regions. Such connections include the ventral and dorsal medullary reticular formation, the dorsal spine nucleus, the parabrachial area, the locus coeruleus,
TABLE 1 | Diagnostic criteria for CPSP.

\begin{tabular}{lr}
\hline Klit et al. (28) & Hansen et al. (30) \\
\hline 1) Pain in an area of the body with & 1) Development of pain with onset of \\
somatotopic correspondence to & ofter the stroke. \\
the CNS lesion. & 2) Pain located on the stroke-affected \\
side of the body. \\
2) Suggestive history of stroke and & 3) No other plausible cause of the \\
the appearance of pain can & pain, including pain isolated to the \\
happen early or with some delay & shoulder joint and nearby region. \\
over time. & \\
3) Confirmation of CNS lesion by & \\
image or positive or negative & \\
sensory signs, with somatotopic & \\
correspondence to the area of & \\
the lesion. & \\
4) Exclusion of other causes that & \\
may explain the painful & \\
symptoms. The supportive & \\
criteria include pain with no & \\
direct relation to movement, \\
inflammation, or tissue damage; \\
descriptors of neuropathic pain \\
like burning, electrical shock, \\
painful cold, aching, pressure, \\
sting, pinprick, and needle; and \\
complaint of allodynia or \\
dysesthesia to the touch or cold.
\end{tabular}

and the periaqueductal gray matter. Additionally, the lateral and medial thalamus, anterior pretectal nucleus, amygdala, and the hypothalamus are also part of the neural network of pain processing. The ascending path is formed by two parallel pain pathways, divided into the medial and lateral systems. The medial system comprises the spinohypothalamic, spinoamygdalar, medial spinothalamic, and spinoreticular tracts. It has connections with the limbic, prefrontal, and cingulate cortices. Furthermore, it is responsible for transmitting information associated with the affective, motivational, and autonomic responses to pain. In contrast, the lateral pathway comprises the spinothalamic tract. This tract transmits information to the lateral thalamus and, later, to the primary and secondary somatosensory cortices, which are responsible for identifying the nociceptive stimulus quality, pain location, and intensity (31). Although, the neuroanatomical connections are known, the mechanisms responsible for the emergence of CPSP remain unclear; however, it is known that they transcend the effect of structural damage. According to theory, a central mechanism is a functional imbalance between the excitatory and inhibitory systems in pain pathways, which can be related to specific neural circuits associated with the neuroanatomical lesion areas.

In 1911, Henry Head and Gordon Holmes (32) proposed the disinhibition theory, intending to explain the change in the perception of painful and non-painful stimuli in individuals with injury to the lateral thalamus. According to these authors, a lateral nucleus injury would lead to loss of cortical control mechanisms. Thus, thalamus hyperactivity and the consequent exacerbated response to stimuli would occur. Later, Craig et al. 
(33), based on this theory, proposed an idea of imbalance between the output of the thermosensory area in the insula and the limbic network associated with thermoregulatory motivation as a consequence of CNS lesion. According to this theory, lesions of the lateral lamina I spinothalamocortical pathway, connected to the parieto-insular cortex by posterolateral thalamus projections, would be related to the disinhibition of nociceptive polymodal activity. This disinhibition takes place in the medial lamina I spinothalamocortical pathway, which is connected to the anterior cingulate cortex. Therefore, there would be loss of thermo-sensorial integration, which manifests itself as a burning sensation and produces exacerbated responses to temperatures previously perceived as harmless.

Other studies corroborate the idea that damage to the spinothalamic pathway is a central mechanism of CPSP. In 1989, Boivie et al. (34) found that injury at any level in this pathway could be responsible for the emergence of CPSP. Vartiainen et al. (35) also demonstrated that impairment of the spinothalamocortical pathway is a predictive factor independent of the development of central pain. In addition to structural lesions of this pathway, CPSP may also occur due to brain plasticity changes (36). This theory posits that dysfunctional neuroplasticity is a central mechanism of CPSP and finds support in the pathophysiology of other neuropathic pain conditions, in which the pathological phenomenon of spontaneous pain is linked to maladaptive mechanisms of cortical and thalamic hyperexcitability (14). Gritsch et al. (37), in a mouse study, showed that mechanical hypersensitivity in CPSP does not depend on the expressions of type I vanilloid-type receptors (TRPV1) on nerve fibers and neurokinin-1 receptors of the spinal cord. They suggest that central pain is due to lateral thalamus hyperexcitability, which is associated with the expressions of calcium-voltage-dependent channels and changes in the GABAergic inhibitory system. Similar results in other animal studies have shown a possible association in the development of CPSP, with increased connections in the affected hemisphere, between the mediodorsal nucleus of the thalamus and the amygdala (38). In addition, in a study by Kuan et al. (39), aberrant neuronal activity in the pathway between the medial thalamus and cingulate cortex, having the brain-derived neurotrophic factor (BDNF) as a mediator, was observed. The authors suggest that, in this type of thalamocortical dysrhythmia, an imbalance in the activity between the GABAergic and glutamatergic systems is involved.

To corroborate this idea, studies using magnetic resonance imaging have shown that individuals with CPSP present a characteristic pattern of cortical atrophy in different regions, which include the temporal, secondary somatosensory, insular, and ventrolateral prefrontal cortices, as well as the nucleus accumbens. These changes indicate anatomical variations that can explain maladaptive alterations associated with the affective component of pain and with discriminatory sensory impairment (36). A later study, using diffusion tensor imaging, found white matter microstructural changes in areas associated with pain processing (i.e., the anterior cingulate cortex, posterior insula, thalamus, and the somatosensory cortex). Also, this study found increased functional connectivity in the anterior cingulate cortex and decreased connectivity in the somatosensory cortex (40). Thus, an integrative approach using neurophysiological measures to understand the relationship between the area of neuroanatomical damage and the physiological state could help diagnose and direct new therapeutic models (37). Figure 1 illustrates the lesion sites involved in the physiopathology of CPSP.

Despite advances in psychopharmacological treatments over the last few decades, their efficacy is limited, and there is a high incidence of adverse effects in CPSP $(41,42)$. Accordingly, it is possible to theorize that this low success rate is related to the limited power of pharmaceuticals to modify the maladaptive neuroplasticity in pain processing pathways. Thus, the motivation to understand dysfunctional neurophysiological processes grows to guide the search for complementary nonpharmacological options. The above-mentioned background gives support to explore how non-pharmacological approaches, such as non-invasive or invasive brain stimulation (43), or other therapeutic approaches, such as hypnotherapy, mindfulness, or cognitive-behavioral therapy, can change pain sensitivity. In a pragmatic view, advancement in the therapeutic field may be more likely to occur if we improve the capacity to characterize the phenotypes of CPSP and evaluate the dysfunction in neuroplasticity processes by neurophysiological measures. Among the tools available, TMS and functional neuroimaging permit us to assess the impacts of treatments on dysfunctional neuroplasticity processes that lead to and maintain CPSP.

\section{TMS MEASUREMENTS AS A POTENTIAL BIOMARKER}

TMS is a non-invasive, versatile, and painless tool for measuring different cortical parameters in vivo (44). TMS measures provide indirect information about the systems responsible for modulating interneuron activity, such as the GABAergic, glutamatergic, and cholinergic pathways. However, these systems are affected by pathological processes in the CNS $(45,46)$.

Among the TMS measures, MEP is the main parameter used in clinical neurophysiology. It represents the excitability/conductivity and the integrity of corticospinal pathways (47). It results from a unique TMS pulse, delivered through a coil located over the scalp, to generate an eddy current that activates transsynaptic pyramidal neurons and results in a muscular action potential recorded through surface electrodes over selected target muscles (48). Another important measure in the scientific field, as well as in clinical practice, is cortical MT. This measure permits the calculation of the individual intensity of the TMS pulse in the subsequent protocol (e.g., an intensity of $80-120 \%$ of the MT) (49). This measure is assessed when the target muscle is at rest. The resting MT (RMT) is the minimal intensity of the TMS pulse to produce an MEP of at least $50 \mathrm{mV}$ in $50 \%$ of the attempts $(47,49)$. Alternatively, active MT (AMT) is assessed during a slight muscular contraction ( $\sim 20 \%$ ) of the target muscle $(47,49)$. It is defined as the minimal pulse intensity to elicit an $\mathrm{MEP} \geq 200 \mu \mathrm{V}$ in $50 \%$ of 


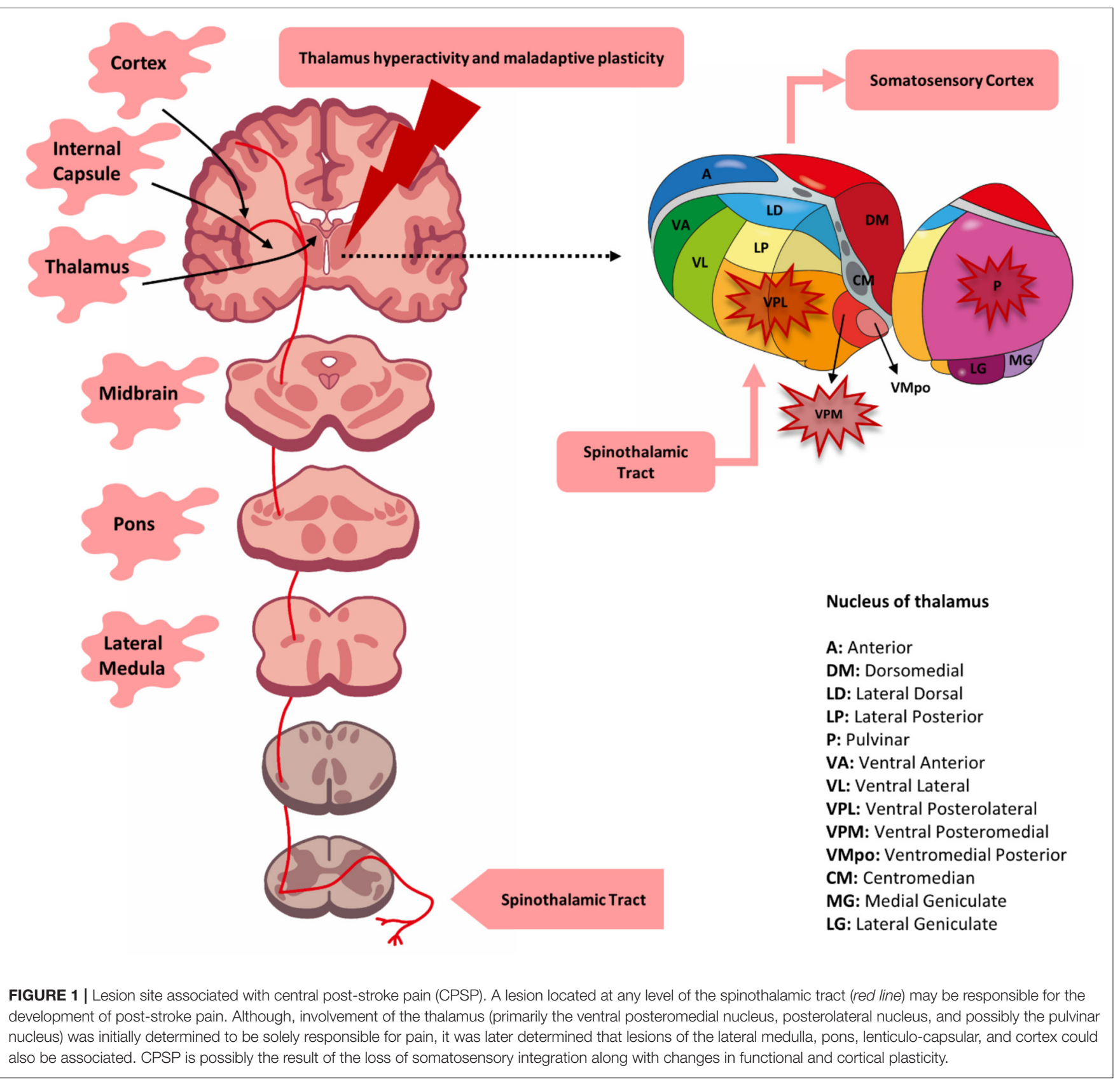

the attempts. It corresponds nearly to the threshold necessary to induce activation in fast-conducting neurons $(46,49)$. While the RMT infers glutamatergic synaptic connections, the AMT is voltage-gated cation channel-dependent $(50,51)$ and infers axonal excitability (52).

TMS measures can also be helpful in the evaluation of inhibitory physiological phenomena. After applying a TMS pulse with suprathreshold intensity over the motor cortex while the subject performs a sustained muscular contraction on the contralateral side of the body, a period of electrical silence on the electromyography activity occurs following the MEP (49). This parameter is referred to as a CSP, and it is mediated, in its early and late phases of EMG suppression, by spinal and supraspinal inhibitory mechanisms, respectively (53).

In addition to a single TMS pulse, a paired-pulse TMS can be useful in assessing inhibitory and facilitatory intracortical circuits. This paradigm comprises a subthreshold conditioning stimulus (CS) followed by a suprathreshold test stimulus (TS). The interstimulus intervals (ISIs) vary from 1 to $20 \mathrm{~ms}$. Furthermore, the MEP amplitude produced by the paired pulse is compared with the TS alone that works as a reference condition $(45,49)$. In practice, the paired pulse applied with an ISI of 1-6 ms and the corresponding MEP amplitude result from a 
cortical inhibitory phenomenon known as SICI (47). The SICI has two phases-the short ISI (around $1 \mathrm{~ms}$ ) is associated with neural refraction, while the second phase of $2.5 \mathrm{~ms}$ is the long interval $(54,55)$ - and reflects synaptic inhibition mediated by GABA type A receptors (56). However, if an ISI of 7-20 ms is applied, the resulting increase in the MEP amplitude is denominated as ICF $(57,58)$. The facilitation phenomenon is related to excitatory glutamatergic circuits. Both SICI and ICF reflect the activity of intracortical circuits dependent on the GABA/glutamate balance (47).

MEP inhibition as a consequence of electrical peripheral nerve stimulation (usually the median nerve at the wrist or with a digit), preceding a subsequent suprathreshold TMS in the contralateral motor cortex, with ISI ranging between 20 and $25 \mathrm{~ms}$, is known as short-latency afferent inhibition (SAI) (48). Pharmacological studies have shown that SAI is related to cholinergic (59) and GABAergic circuits (60). This measure can assess the inhibitory circuits between hemispheres (interhemispheric inhibition) and cerebellar-cortical connections. Interhemispheric modulation can be tested by applying two TMS pulses at ISIs in each hemisphere (61). In the same way, cerebellar brain inhibition (CBI) is assessed when the MEP amplitude is reduced after a TMS pulse in the cerebellum, followed by a second pulse applied in the motor cortex (M1) (62).

Different studies have shown that TMS measurements can be helpful to understand the development, prognosis, and therapeutic approach of various pathological processes and specific diseases. For instance, in the case of vascular dementia ( $\mathrm{VaD}$ ) and Alzheimer's disease, a decrease in SAI has been observed ( $25 \%$ of subjects in VaD). Additionally, pathological reduction of the MT and intracortical inhibition (ICI) are parameters that indicate imbalance in the glutamatergic, GABAergic, or the cholinergic system (63).

Likewise, in patients with pain, cortical excitability measurements can reflect descending pain modulatory system function, and their variations are associated with the clinical response to exogenous approaches, such as physical activity, TMS, or transcranial direct current stimulation $(64,65)$. Poststroke TMS neurophysiological measures present a prognostic value of adaptive mechanisms in both acute and chronic phases (66). Thus, variations in the $\mathrm{CE}$ measures as a reflection of maladaptive plasticity may be fundamental in building a critical integrative perspective of CPSP, either in diagnosis or treatment.

\section{TMS Measurements in Stroke}

In healthy subjects, a study by Mills and Nithi (67) evaluated MT and its relationship with several variables, such as gender, age, and the hemisphere assessed. They demonstrated a positive correlation in the MT value and no differences in the means between hemispheres. Conversely, after stroke, the MT is in the normal range in the unaffected hemisphere, both in the acute $(68-70)$ and chronic phases $(69,71)$. However, in the affected hemisphere, the MT is usually increased compared to the unaffected hemisphere or compared to healthy subjects, either in the acute $(68-70,72,73)$ or subacute phase $(70,74,75)$. After the subacute phase, the MT decreases progressively over time (76). This phenomenon is associated with a cortical recovery process from axonal remyelination secondary to oligodendrocytic cellular precursor maturation (77). Furthermore, some studies have confirmed the presence of asymmetries in MT according to the location of the lesion, whether in cortical or subcortical structures. A study by Delvaux et al. (78) evaluated MT in cortical and cortico-subcortical stroke and did not identify a statistically significant difference in the comparison of the affected hemisphere with controls. Alternatively, other studies have found increased MTs in subcortical lesions $(74,79)$. The purported biological cause of this finding was damage to the neural fibers essential for responsiveness to TMS stimuli (80).

Like MT, MEP presents changes when evaluated in the affected hemisphere of stroke patients. In general, MEP has a decreased amplitude when compared to the amplitude of the unaffected side or the same hemisphere of healthy subjects $(70,73,81)$. However, in some cases, a progressive MEP increase related to motor recovery of the participant was identified $(69,82)$. Usually, in the unaffected hemisphere, changes in MEP have not been observed $(69,70)$. Despite this, several studies have shown an increase in the acute phase after the stroke, with a subsequent tendency to normalize over time $(78,83)$. These initial cortical changes, located contralateral to the lesion, may occur due to a decreased GABAergic inhibitory activity and to alteration in transcallosal balance, both of which are consequent to neuronal ischemia (78).

MEP can be fundamental in understanding and directing the rehabilitation of patients after stroke. This is a neurophysiological measure that provides information related to corticospinal tract function and is capable of predicting the motor recovery of patients in the first weeks after injury $(70,76,84)$. Thus, besides having prognostic properties, the absence or presence of MEP during the evaluation of a specific muscle may suggest the beginning of a rehabilitation plan to recover muscle functionality in patients with integrity, or at least some level of corticospinal pathway function (presence of MEP), or the implementation of compensatory treatment in cases of insufficient response (reduced or absent MEP) (85). Additionally, there is the possibility that MEP responses following the initial physical therapy sessions (goal-oriented task) can provide information on the therapeutic effectiveness of the intervention in the acute phase (86).

Like the previously mentioned cortical measurements of stroke, SICI, ICF, and CSP present specific patterns. Following stroke, SICI is reduced (87). This finding seems to be related to the structural damage severity and vascular lesion location. Huynh et al. (88) explored the relationship between the severity of brain injury and the SICI level in the affected hemisphere. They showed that the reduction in SICI was proportional to the degree of impairment due to sequelae after the stroke and found decreased SICIs in both cortical and subcortical lesions, leading to a more significant reduction in those with cortical lesions than in controls. Conversely, studies that have investigated the SICI in the unaffected hemisphere showed a decrease in this measure associated with the cortical location and the initial phase of stroke. However, the measure was not related to lesion extension or patients' motor recovery (89). A plausible explanation for this phenomenon was cortical plasticity reorganization as a 
response to vascular injury $(90,91)$ and loss of interhemispheric relationship integrity as a consequence of the imbalance of facilitation and inhibition interactions between the hemispheres (92). In the chronic phase of stroke, although, a decrease in SICI has been shown $(93,94)$, a meta-analysis conducted by McDonnell and Stinear (95) found an inconsistent SICI pattern when the affected hemisphere was compared with the unaffected hemisphere and healthy controls. Concerning ICF, the impact of acute and chronic stroke on this measure is less clear. There were no differences or consistency between the hemispheres or in the comparison with healthy controls at any time (95-97).

Despite CSP presenting significant inter-individual variability, small intra-individual differences between hemispheres were found. Therefore, its measurement allows an adequate assessment of unilateral changes (98). Regarding CSP behavior in stroke, studies have found that CSP tends to be prolonged in the acute phase after stroke (1-7 days) $(87,95,99,100)$. This finding could be interpreted as a consequence of the reduced ICI of inhibitory interneurons. It also reflects the presence of adaptive processes that favor an intracortical excitation state (101). Conversely, in subacute and chronic stroke, various CSP patterns (e.g., regular, shortened, or prolonged) were found. The authors suggest that this variability is due to the influence of variables such as lesion location or the presence of spasticity (98). In focal lesions of the motor cortex, the CSP may be decreased or absent due to impairments in cortical inhibitory interneurons (102). However, cortical and subcortical lesions distant from this region (motor cortex) extend the CSP due to cortical disinhibition related to the loss of the modulating projections to the motor cortex $(99,103)$. The presence of spasticity in patients in the chronic phase of stroke was related to a shortening of the CSP due to the decreased activity of the inhibitory circuits $(104,105)$.

\section{TMS Measurements in Pain}

In cases of pain not explicitly related to stroke, we can better characterize the pathophysiological mechanisms involved in its development and evolution with the help of TMS measurements in the M1. When comparing acute and chronic pain of different etiologies, we found a critical variability in the MEP and MT. In acute experimental pain, the use of varying nociceptive stimuli, such as heat (106), cold (107), and capsaicin (108), reduced the MEP. This result was confirmed by data from a meta-analysis conducted by Burns et al. (109). The meta-analysis evaluated the effect and changes in cortical activity in the brain regions corresponding to the primary somatosensory cortex (S1) and primary motor cortex (M1) in acute myofascial pain. They found that the MEP decreased during the application of a painful stimulus (hypertonic saline solution and ascorbic acid). According to the authors, the cortical inhibition phenomenon in the M1 region occurred to limit motor activity and to avoid worsening the tissue injury and increasing pain.

In chronic pain, a reversal of this phenomenon may occur with increased MEP. This amplified MEP response in chronic pain has been interpreted as a cortical reorganization due to an imbalance between the inhibitory and excitatory systems (110112). Interestingly, although, the MT increased in some cases
$(113,114)$, it tended to remain unchanged in both acute (115) and chronic pain $(65,116)$ in most studies.

In addition to the MEP and MT, there are variations in other intracortical measurements associated with the pain that emerges during different pathological processes. Salo et al. (107) used an experimental model of acute pain in which a stimulus with cold water was applied to the right hand to simulate the effect of neuropathic pain on cortical activity. The study showed an increase of SICI in TMS evaluation. Another study on acute myofascial pain found an association with decreasing ICF (117). Moreover, a review and meta-analysis conducted by Parker et al. (118) on subjects with chronic pain demonstrated a significant reduction in CSP duration and SICI amplitude and an increase in ICF. Similarly, results were found that point to decreases in the CSP and ICI in different pathologies. Among them were osteoarthritis, myofascial pain, fibromyalgia (112), rheumatoid arthritis (114), CPSP, syringomyelia, brachial plexus injury, and median nerve peripheral neuropathy (65).

Measures of the CE parameters have already been shown to be important in the study and understanding of endogenous analgesic systems in healthy individuals and in patients with chronic pain. According to Granovsky et al. (64), in healthy individuals, there is a positive correlation between the amplitude and duration of MEP and the antinociceptive mechanisms evaluated by conditioned pain modulation (CPM). However, in chronic pain, MEPs of greater amplitude recorded in individuals with myofascial pain syndrome had no relation with a more efficient CPM response (111). Lefaucheur et al. (65) highlighted the importance of understanding the interaction between antinociception phenomena and CE. The therapeutic use of high-frequency TMS $(10 \mathrm{~Hz})$ in chronic neuropathic pain produced adequate analgesic responses related to ICI increase. Changes in ICI after repetitive TMS were linked to the recovery of GABAergic neurotransmitter activity (119).

\section{Cerebellum and TMS Measurements}

The TMS model of paired stimulus permits quantification of the inhibitory tonus that the cerebellum exerts on the motor cortex, which is referred to as cerebellar brain inhibition (CBI) (62). Daskalakis et al. (120) found an inversely proportional relationship between SICI and CBI in healthy subjects. The interaction between the cerebellar and cortical circuits was explained by the activation of Purkinje cells with inhibitory activity by the magnetic impulse (121). Thereby, this inhibitory activity suppresses the excitatory stimuli from deep cerebellar nuclei and the ventrolateral thalamus nucleus. This chain effect could explain the decrease observed in the expression of cortical inhibitory mechanisms (i.e., SICI) (Figure 2). Conversely, in this same study, the researchers observed an increase in ICF dependent on the decrease in SICI. The authors interpreted that these findings were due to the imbalance between the excitatory and inhibitory cortical circuits (120).

In patients with CPSP, the effect of the cerebellum on cortical activity in the M1 may be relevant if we consider that, by adaptive mechanisms, pain induces motor changes that seek to protect the body and avoid nociceptive stimulus (122). Although, previous studies have focused on assigning this response to 


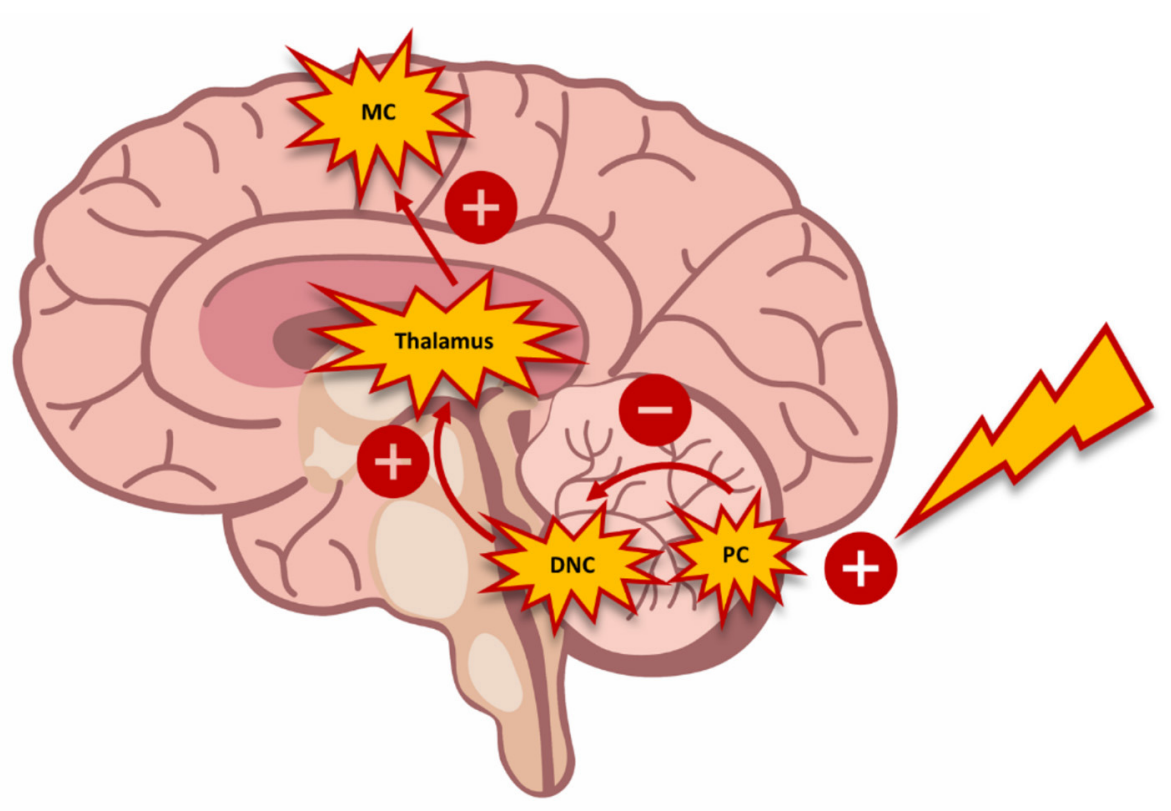

FIGURE 2 | Schematic diagram demonstrating the interaction between the cerebellum and the motor cortex. The activation of Purkinje cells (PC) with inhibitory connections suppresses exiting stimuli from the deep cerebellar nuclei $(D C N)$ and the ventrolateral nucleus of the thalamus toward the motor cortex (MC). The inhibition of this circuit triggers changes in motor control, which can be measured through transcranial magnetic stimulation.

cortical areas (123), recent studies have linked this response to the cerebellum (specifically the posterior lobules VIe and VIIb). These cerebellar areas are associated with the anterior cingulate cortex, supplementary motor area, and the thalamus. Therefore, it is plausible that this adaptive motor response is due to the interplay of the regions involved in pain processing and the cerebellar circuits (124).

\section{METHODS}

The methodology of the current systematic review was based on the PRISMA (Preferred Reporting Items for Systematic Reviews and Meta-Analysis) guidelines. There has not been a previously published protocol in PROSPERO (International Prospective Register of Systematic Reviews) before the development of this study.

Relevant studies were sought in EMBASE (from 1993), PubMed (from 1996), and ScienceDirect (from 1997) databases. The MeSH or Entree terms used, and their combinations, were as follows: [("Cerebral Stroke") AND ("Pain" OR "Transcranial Magnetic Stimulation") AND ("Transcranial Magnetic Stimulation”)] (through September 29, 2020).

\section{Criteria for Inclusion and Exclusion and Quality Analysis of Studies}

We defined the following criteria to include a paper to the meta-analysis: studies in humans; written in English, Spanish, or Portuguese; the focus was on CPSP; use of TMS measures to evaluate cortical function; and quantitative results were provided.
No filter was applied concerning the publication year or the study design.

Two authors independently evaluated and selected the included studies. If there was disagreement, those specific cases were discussed with a third evaluator. After the initial identification of the studies using the search strategy, duplicate articles were excluded and a second screening was performed, in which reports on animals and studies that were not related to the research question were discarded. Studies that included the phrases "post stroke pain," "poststroke pain," "post-stroke pain," "central pain," "central neuropathic pain," "Dejerine-Roussy syndrome," "thalamic pain," "thalamic syndrome," "Wallenberg syndrome," and "central and peripheral neuropathic pain" were considered relevant. In the next step, the abstracts of 297 articles were evaluated to identify and exclude studies that did not use TMS as a therapeutic or diagnostic measure. The texts were then thoroughly evaluated; if the study was eligible, the following information was extracted: study category, sample size, mean age, stroke location, degree and duration of pain, TMS protocol, and the evaluated TMS measures.

\section{Bias Risk Assessment}

Two authors independently evaluated the risk of bias related to the methodological aspects of each study according to the guidelines of the National Institutes of Health (NIH). In case of disagreement, interpretation differences were discussed between the authors, with a third reviewer's participation if necessary. The main characteristics evaluated were: research question, study population, uniform eligibility criteria and characteristics of the recruited population, justification of the sample size, outcome 


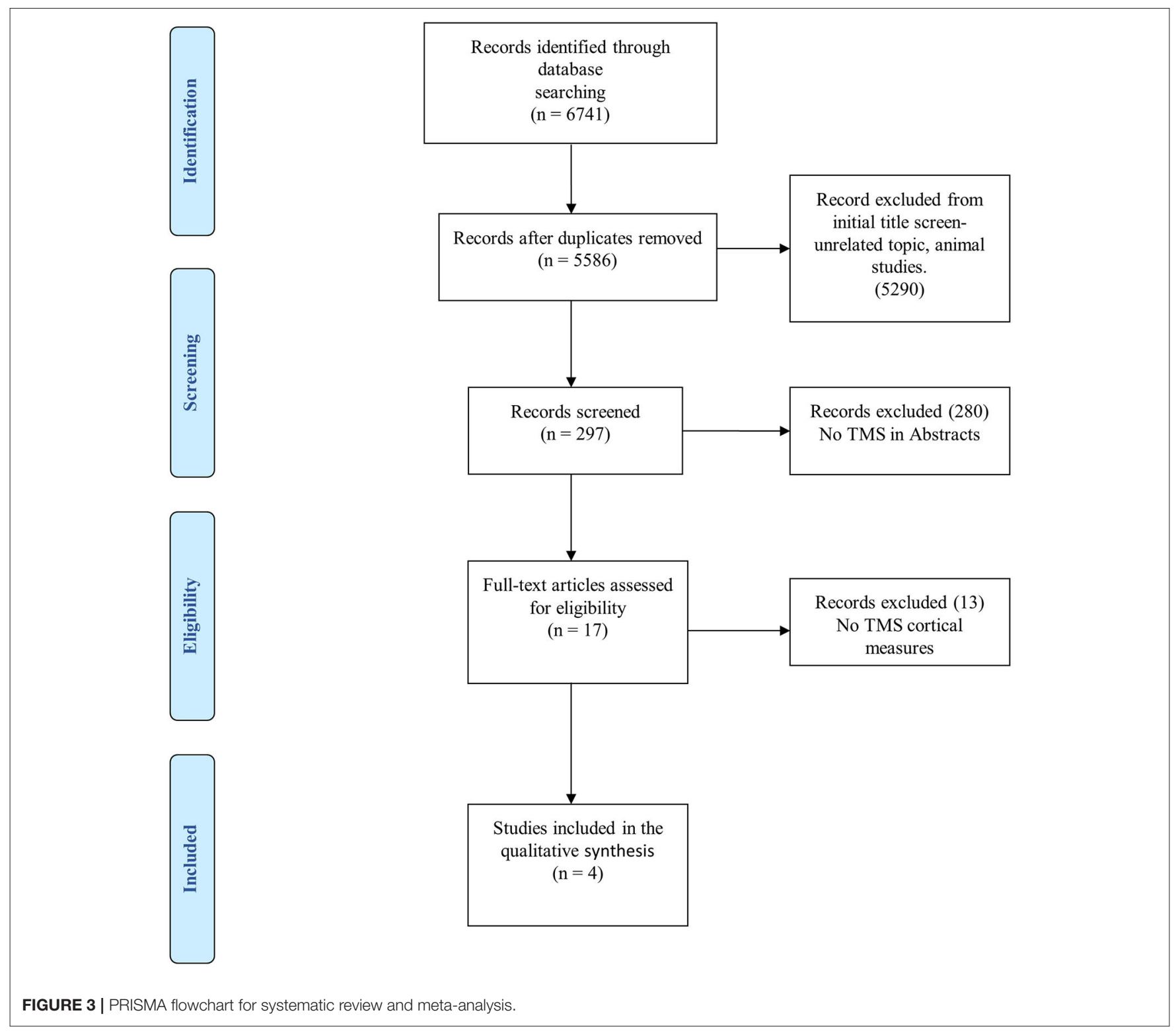

evaluation, blinding, follow-up, and statistical analysis. After the analysis, the risk of bias of each study was classified as good, fair, or poor. It is essential to mention that the topic analyzed and the number of questions used during the quality evaluation could change according to the methodology of each article (Table 4).

\section{RESULTS}

The search strategy is summarized in Figure 3, as indicated in the PRISMA flowchart (129). Initially, a total of 6,741 articles were identified. After discarding animal studies and those without a title associated with the research question, this number decreased to 297. Following this, we reviewed the abstract of each study and excluded those that did not use TMS as a tool for diagnosis. Finally, after analyzing 17 articles, only four quantitatively reported CE indexed by TMS assessment.

\section{Demographic Characteristics of the Patients Included}

The demographic and clinical characteristics of the study samples are presented in Table 2 . The four reviewed articles included a total of 67 participants diagnosed with CPSP and 22 participants as controls. All subjects were adults, with a mean age of 59.5 years $(\mathrm{SD}=6.5)$ in those with central pain and 55.7 years $(\mathrm{SD}$ $=4.5$ ) in control subjects. CPSP was most prevalent in males, with a total of 46 participants $(68.6 \%)$. The following data were extracted regarding the anatomical location of the lesion and the compromised body segment: 39 participants had hemorrhagic and 28 had ischemic lesions. Subcortical structure impairment was the most prevalent, with a total of 54 cases (31 in the thalamus, 11 in the putamen, 1 in the internal capsule, and 11 unspecified). The second most affected site was the brainstem, affected in nine subjects (three in the lateral bulb, two in the 
TABLE 2 | Sample characteristics and central nervous system drugs used currently $(n=67)$.

\begin{tabular}{|c|c|c|c|c|c|c|c|c|c|c|}
\hline Reference & $\begin{array}{l}\text { Study } \\
\text { design }\end{array}$ & $\begin{array}{l}\text { No. of } \\
\text { patients } \\
\text { (E/C) }\end{array}$ & $\begin{array}{l}\text { Sex: } \\
\text { E/C }\end{array}$ & $\begin{array}{l}\text { Age: } \\
\text { E/C }\end{array}$ & $\begin{array}{l}\text { Stroke } \\
\text { etiology }\end{array}$ & $\begin{array}{l}\text { Stroke } \\
\text { areas }\end{array}$ & $\begin{array}{c}\text { Pain } \\
\text { duration } \\
\text { (months) }\end{array}$ & $\begin{array}{l}\text { Baseline } \\
\text { pain } \\
\text { score }\end{array}$ & $\begin{array}{l}\text { Current } \\
\text { medication }(N)\end{array}$ & $\begin{array}{c}\text { Washout } \\
\text { period }\end{array}$ \\
\hline $\begin{array}{l}\text { Hosomi et al. } \\
\text { (126) }\end{array}$ & $\begin{array}{l}\text { Before and } \\
\text { after study }\end{array}$ & $29(21 / 8)$ & $12 / 8 \mathrm{M}$ & $60(9) / 53(10)$ & $\begin{array}{l}\text { Hemorrhagic } \\
\text { (17) } \\
\text { Ischemic (4) }\end{array}$ & $\begin{array}{l}\text { Thalamus (8) } \\
\text { Putamen (7) } \\
\text { Brain stem (4) } \\
\text { Subcortex (2) }\end{array}$ & $47(55)$ & 78 & $\begin{array}{l}\text { TCA (9), SSRI (4), } \\
\text { BZD (6), NSAID (4), } \\
\text { CZP (5), GBP (11), } \\
\text { PB (1), MEX (2), ZNS } \\
\text { (1), PHT (1) }\end{array}$ & $\mathrm{NI}$ \\
\hline $\begin{array}{l}\text { Tang et al. } \\
\text { (125) }\end{array}$ & $\begin{array}{l}\text { Cross- } \\
\text { sectional } \\
\text { study }\end{array}$ & $28(14 / 14)$ & $12 / 12 \mathrm{M}$ & $\begin{array}{c}58(8.9) / 59 \\
(9.1)\end{array}$ & $\begin{array}{l}\text { Hemorrhagic (6) } \\
\text { Ischemic (8) }\end{array}$ & $\begin{array}{l}\text { Thalamus (8) } \\
\text { Putamen (1) } \\
\text { Pons (2) } \\
\text { Lateral medulla } \\
\text { (2) } \\
\text { Internal capsule } \\
\text { (1) }\end{array}$ & $40(36)$ & $5.0(1.4)$ & $\begin{array}{l}\text { DXT (5), IMI (4), CZP } \\
\text { (3), PNG (1), OXC (1) }\end{array}$ & 3 days \\
\hline $\begin{array}{l}\text { Hasan et al. } \\
\text { (127) }\end{array}$ & $\begin{array}{l}\text { Before and } \\
\text { after study }\end{array}$ & $14(14 / 0)$ & $10 M$ & 57 & $\begin{array}{l}\text { Hemorrhagic (3) } \\
\text { Ischemic (11) }\end{array}$ & $\begin{array}{l}\text { Cortex (5) } \\
\text { Subcortex (9) } \\
\text { Lateral medulla } \\
\text { (1) }\end{array}$ & $\mathrm{Nl}$ & $\geq 4$ & $\begin{array}{l}\text { PNG (8), CTP (7), } \\
\text { AMP (3), TMD (1), } \\
\text { MLT (1), NTP (1) } \\
\text { GBP (1), KTM (1), } \\
\text { MPN (1) }\end{array}$ & $\mathrm{NI}$ \\
\hline $\begin{array}{l}\text { Kobayashi et } \\
\text { al. (128) }\end{array}$ & $\begin{array}{l}\text { Before and } \\
\text { after study }\end{array}$ & $18(18 / 0)$ & $12 \mathrm{M}$ & $63(9.9)$ & $\begin{array}{l}\text { Hemorrhagic } \\
\text { (13) } \\
\text { Ischemic (5) }\end{array}$ & $\begin{array}{l}\text { Thalamus (15) } \\
\text { Putamen (3) }\end{array}$ & $9(6.8)$ & $>70$ & $\begin{array}{l}\text { SSRI (3), AMP (8), } \\
\text { CBZ (2), CZP (1), } \\
\text { GBP (1), PGN (1) }\end{array}$ & $\mathrm{NI}$ \\
\hline
\end{tabular}

SSRI, selective serotonin reuptake inhibitor; AMP, amitriptyline; CBZ, carbamazepine; CZP, clonazepam; GBP, gabapentin; PNG, pregabalin; TCA, tricyclic antidepressant; BZD, benzodiazepine; NSAID, non-steroidal anti-inflammatory; PB, phenobarbital; MEX, mexiletine; ZNS, zonisamide; PHT, phenytoin; DXT, duloxetine; IMI, imipramine; OXC, oxcarbazepine; CTP, citalopram; TMD, tramadol; MLT, melatonin; NTP, nortriptyline; KTM, ketamine; MPN, morphine; NI, no information; $M$, male; $E$, experimental group; $C$, control group. 
pons, and four in unspecified areas). Cortex impairment occurred in five non-reported regions. Pain level was determined using a numerical pain scale, with values between 0 and 100 in two studies and between 0 and 10 in the other two studies. The median (and interquartile range, IQ 25-75) of pain duration in months was equal to 38 (IQ $=9-47$ ). Pain was located in the hemi-body and the upper limb in 58 cases and in the lower limb in nine subjects.

\section{MEP and MT}

The principal basal quantitative measures are presented in Table 3. The reviewed studies performed CE measurements in the $\mathrm{M} 1$ region contralateral to the compromised body segment. Two studies evaluated MEP in the first dorsal interosseous and short abductor thumb muscles $(125,126)$. In the other studies, the recording was performed in the anterior tibial and the first dorsal interosseous $(127,128)$. The cumulative mean of the RMT in the affected hemisphere evaluated in three studies was equal to $55.2 \%(\mathrm{SD}=8.9)$. One of these studies determined the AMT, with a mean of $58.9 \%(S D=12)(128)$. They compared the RMT values between the unaffected hemisphere and healthy controls. The mean RMT values in different studies for the unaffected hemisphere and healthy subjects were $48.9 \%$ (SD $=10.7)$ and $52.8 \%(\mathrm{SD}=8.5)$, respectively. In the study by Hosomi et al. (126), the RMT was $65.5 \%$ (SD = 14) in the affected hemisphere compared with a threshold of $56.7 \%$ (SD $=6.5$ ) in healthy subjects, which was a statistically significant difference $(P=0.035)$. In contrast, the other studies found no statistically significant difference when comparing the RMT of stroke patients with controls. In the studies that showed dispersion of RMT values using standard error variation, the standard deviation was calculated to quantify the median value between studies.

Another basal measurement evaluated in Hasan et al. (127) and Hosomi et al. (126) was the MEP amplitude with $120 \%$ of MT. They compared the MEP measures of the injured hemisphere with the contralateral hemisphere and healthy controls. Only one study recorded MEP latency in the hemispheres of CPSP patients (127).

\section{Paired Pulse Measures and CSP}

Tang et al. (125) noted that the variations in ICF and SICI measurements were analyzed compared to patients with CPSP and healthy individuals. Different ISIs were implemented, and the mean amplitude of the MEP of each one was normalized to the mean amplitude of the individual test stimulus. In the unaffected hemisphere, MEP was inhibited in the ISI of $3 \mathrm{~ms}(P$ $=0.01)$ and was facilitated in the ISI of $15 \mathrm{~ms}(P=0.05)$. In the affected hemisphere, there was no presence of SICI, but rather facilitation in ISIs of $5,7,10$, and $15 \mathrm{~ms}(P=0.05,0.01,0.05$, and 0.01 , respectively). Similarly, in the hemispheres of healthy subjects, inhibition of MEP was demonstrated in the interval of $3 \mathrm{~ms}(P=0.01)$ and its facilitation in 10,15 , and $20 \mathrm{~ms}(P=0.01$, 0.01 , and 0.01 and $P=0.01,0.01$, and 0.05 in the control-matched stroke and unaffected hemispheres, respectively).

The CSP, SICI, and ICF were reported identically in the study of Hosomi et al. (126), being quantified among participants with central pain, comparing them with healthy individuals. Although, none of these measures showed statistically significant differences between groups, it is important to mention the trend in CSP enlargement, and the decreases in ICF and SICI in the affected hemisphere, when compared with healthy controls. Only Tang et al. (125) recorded the SAI and long-latency afferent inhibition in the hemispheres of CPSP patients.

\section{BIAS RISK ASSESSMENT}

The risk of bias, evaluated by the NIH criteria, of the four studies included in this review is presented in Table 4. In general, the main limitations of the studies are related to a lack of a clear description of the population studied, sample size calculation, and the blinding of participants or evaluators. The studies of Hasan et al. (127) and Kobayashi et al. (128) showed low methodological quality due to selection and information bias. They did not clearly describe the inclusion and exclusion criteria and the parameters for estimating the sample size and did not apply blinding to the evaluators. Although, the other two articles $(125,126)$ did not report a form of blinding or the parameters used to calculate the sample size, they clearly described the inclusion and exclusion criteria and, thus, were classified as having fair and good methodological quality, respectively.

\section{DISCUSSION}

This systematic review allowed us to integrate data related to TMS measurements, somatotopic information of stroke, and clinical parameters in individuals with CPSP diagnosis. Considering the diversity of the clinical symptoms, the limited response to available treatments, and the different protocols for obtaining CE measurements, it is possible to affirm that these data are relevant to advance this field of knowledge. Because of the negative impact of CPSP on quality of life, the relevance of this subject is unquestionable, especially given the high prevalence of cerebrovascular disease in the population and the emergent demand to advance rehabilitation in stroke patients. Among the several methodological aspects, we highlighted those related to the study outcomes regarding the functional diagnosis by measures of $\mathrm{CE}$. The main limitations were the heterogeneity in the parameters measuring $\mathrm{CE}$, a lack of knowledge regarding $\mathrm{CE}$ measures as potential prognostic markers, differences in the severity and time of disease, a lack of controls with stroke and without pain, and the absence of consistent and validated diagnosis criteria. Unfortunately, it is not possible to assess the impact of drugs on CE (e.g., antidepressants and anticonvulsants), and it was not adequately reported how these $\mathrm{CE}$ measures relate to functional disability determined by poststroke sequela. Finally, due to the reduced number of studies and small sample sizes, which increase the selection bias, readers are cautioned on the generalizability of the current findings.

\section{Integration of the Findings}

The findings of this review suggest that CE measures acquired by TMS permitted us to evaluate the neurobiological systems involved in CPSP. Although, we found few studies, our analysis 
TABLE 3 | Cortical excitability measurements.

\begin{tabular}{|c|c|c|c|c|c|c|c|c|c|c|c|}
\hline Reference & $\begin{array}{l}\text { Reference } \\
\text { muscle }\end{array}$ & Coil type & RMT & AMT & $\begin{array}{l}\text { MEP } \\
\text { amplitude }\end{array}$ & CSP & $\begin{array}{l}\text { Paired pulse } \\
\text { stimulation intensity } \\
\text { (MT, \%) } \\
\text { and interstimulus } \\
\text { interval }\end{array}$ & ICF & & $\mathrm{SICl}$ & \\
\hline \multirow[t]{2}{*}{$\begin{array}{l}\text { Hosomi } \\
\text { et al. } \\
\text { (126) }\end{array}$} & APB & $\begin{array}{l}\text { Figure } 8 \text { coil, } \\
70 \mathrm{~mm}\end{array}$ & $\begin{array}{l}\text { Patients: } \\
65.5 \%(3)^{\star}\end{array}$ & NA & $\begin{array}{l}\text { Patients: } \\
655 \mu \mathrm{V}(80)\end{array}$ & $\begin{array}{l}\text { Patients: } \\
\text { 167.9 ms } \\
(10.4)\end{array}$ & $\begin{array}{l}\text { CS: } 80 \% \text { RMT } \\
\text { TS: } 120 \% \text { RMT } \\
\text { 2, } 4,10 \text {, and } 15 \mathrm{~ms}\end{array}$ & $\begin{array}{l}\text { Patients: } \\
158.6 \%(16.5) \\
\text { ISIs: } 10 \text { and } \\
15 \mathrm{~ms}\end{array}$ & $\uparrow$ & $\begin{array}{l}\text { Patients: } \\
32.0 \%(8.7) \\
\text { ISIs: } 2 \text { and } \\
4 \mathrm{~ms}\end{array}$ & $\uparrow$ \\
\hline & & & $\begin{array}{l}\text { Controls: } \\
56.7 \%(2.3)^{\star}\end{array}$ & & $\begin{array}{l}\text { Controls: } \\
707 \mu \vee(105)\end{array}$ & $\begin{array}{l}\text { Controls: } \\
148.4 \mathrm{~ms}(8.7)\end{array}$ & & $\begin{array}{l}\text { Controls: } \\
168 \%(18.8) \\
\text { ISIs: } 10 \text { and } \\
15 \mathrm{~ms}\end{array}$ & $\uparrow$ & $\begin{array}{l}\text { Controls: } \\
47.3 \%(7) \\
\text { ISls: } 2 \text { and } \\
4 \mathrm{~ms}\end{array}$ & $\uparrow$ \\
\hline \multirow[t]{4}{*}{$\begin{array}{l}\text { Tang et al. } \\
\text { (125) }\end{array}$} & FDI & $\begin{array}{l}\text { Figure } 8 \text { coil, } \\
40 \mathrm{~mm}\end{array}$ & $\begin{array}{l}\text { Stroke } \\
\text { hemisphere: } \\
49 \% \text { (12.6) }\end{array}$ & NA & NA & NA & $\begin{array}{l}\text { CS: } 70 \% \text { RMT } \\
\text { TS: } 125 \% \text { RMT } \\
\text { 3, 5, } 7,10,15 \text {, and } 20 \\
\text { ms }\end{array}$ & $\begin{array}{l}\text { Stroke } \\
\text { hemisphere } \\
\text { ISIs: } 5,7,10 \text {, } \\
\text { and } 15 \mathrm{~ms}^{\star}\end{array}$ & $\uparrow$ & $\begin{array}{l}\text { Stroke } \\
\text { hemisphere } \\
\text { SICl not } \\
\text { detected }\end{array}$ & \\
\hline & & & $\begin{array}{l}\text { Unaffected } \\
\text { hemisphere: } \\
49.5 \%(8.5)\end{array}$ & & & & & $\begin{array}{l}\text { Unaffected } \\
\text { hemisphere } \\
\text { ISI: } 15 \mathrm{~ms}^{\star}\end{array}$ & $\uparrow$ & $\begin{array}{l}\text { Unaffected } \\
\text { hemisphere } \\
\text { ISI: } 3 \mathrm{~ms}^{\star}\end{array}$ & $\uparrow$ \\
\hline & & & $\begin{array}{l}\text { Control } \\
\text { stroke } \\
\text { hemisphere: } \\
48.9 \%(10.3)\end{array}$ & & & & & $\begin{array}{l}\text { Control } \\
\text { Stroke } \\
\text { hemisphere } \\
\text { ISls: } 10,15 \text {, } \\
\text { and } 20 \mathrm{~ms}^{*}\end{array}$ & $\uparrow$ & $\begin{array}{l}\text { Control } \\
\text { Stroke } \\
\text { hemisphere } \\
\text { ISI: } 3 \mathrm{~ms}^{*}\end{array}$ & $\uparrow$ \\
\hline & & & $\begin{array}{l}\text { Control } \\
\text { Unaffected } \\
\text { hemisphere: } \\
51.6 \%(10.7)\end{array}$ & & & & & $\begin{array}{l}\text { Control } \\
\text { Unaffected } \\
\text { hemisphere } \\
\text { ISIs: 10, 15, } \\
\text { and } 20 \mathrm{~ms}^{\star}\end{array}$ & $\uparrow$ & $\begin{array}{l}\text { Control } \\
\text { Unaffected } \\
\text { hemisphere } \\
\text { ISI: } 3 \mathrm{~ms}^{*}\end{array}$ & $\uparrow$ \\
\hline \multirow[t]{2}{*}{$\begin{array}{l}\text { Hasan } \\
\text { et al. } \\
\text { (127) }\end{array}$} & $\begin{array}{l}\text { FDI } \\
\text { ATM }\end{array}$ & $\begin{array}{l}\text { Figure } 8 \text { coil, } \\
90 \mathrm{~mm}\end{array}$ & $\begin{array}{l}\text { Stroke } \\
\text { hemisphere: } \\
51.1 \%(4.0)\end{array}$ & NA & $\begin{array}{l}\text { Stroke } \\
\text { hemisphere: } \\
0.99 \mathrm{mV}(0.2)\end{array}$ & NA & NA & NA & & NA & \\
\hline & & & $\begin{array}{l}\text { Unaffected } \\
\text { hemisphere: } \\
48.3 \%(3.5)\end{array}$ & & $\begin{array}{l}\text { Unaffected } \\
\text { hemisphere: } \\
1.12 \mathrm{mV}(0.2)\end{array}$ & & & & & & \\
\hline $\begin{array}{l}\text { Kobayashi et } \\
\text { al. } \\
\text { (128) }\end{array}$ & $\begin{array}{l}\text { FDI } \\
\text { ATM }\end{array}$ & $\begin{array}{l}\text { Figure } 8 \text { coil, } \\
70 \mathrm{~mm}\end{array}$ & NA & $58.9 \%(12)$ & NA & NA & NA & NA & & NA & \\
\hline
\end{tabular}

$\uparrow$ Indicates an increase or a decrease in SICl and ICF and their intensity.

APB, abductor pollicis brevis; FDI, first dorsal interosseous; ATM, anterior tibial muscle; RMT, resting motor threshold; MEP, motor evoked potential; AMT, active motor threshold; CSP, cortical silent period; ISI, interstimulus interval; NA, not assessed; CS, conditioning stimulation; TS, test stimulation; ICF, intracortical facilitation; SICl, short-interval intracortical inhibition.

${ }^{*} P<0.05$ 
TABLE 4 | Assessment of risk of bias of the reviewed studies $(n=4)$.

\begin{tabular}{|c|c|c|c|c|c|c|c|c|c|c|c|c|c|c|c|}
\hline \multirow[t]{2}{*}{ Methodology } & \multicolumn{14}{|c|}{ Questions } & \multirow[t]{2}{*}{ Rating } \\
\hline & 1 & 2 & 3 & 4 & 5 & 6 & 7 & 8 & 9 & 10 & 11 & 12 & 13 & 14 & \\
\hline 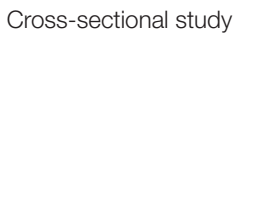 & $\begin{array}{l}\text { Research } \\
\text { question }\end{array}$ & $\begin{array}{l}\text { The study } \\
\text { population } \\
\text { clearly } \\
\text { specified } \\
\text { and } \\
\text { defined }\end{array}$ & $\begin{array}{l}\text { The study } \\
\text { population } \\
\text { rate of } \\
\text { eligibility at } \\
\text { least } 50 \%\end{array}$ & $\begin{array}{l}\text { Groups } \\
\text { recruited } \\
\text { and } \\
\text { uniform } \\
\text { eligibility } \\
\text { criteria }\end{array}$ & $\begin{array}{c}\text { Sample } \\
\text { size } \\
\text { justification }\end{array}$ & $\begin{array}{l}\text { Exposure } \\
\text { assessed } \\
\text { prior } \\
\text { to outcome } \\
\text { measurement }\end{array}$ & $\begin{array}{l}\text { Sufficient } \\
\text { time frame } \\
\text { to see an } \\
\text { effect } \\
\text { tt }\end{array}$ & $\begin{array}{l}\text { Different } \\
\text { levels of } \\
\text { the } \\
\text { exposure } \\
\text { of interest }\end{array}$ & $\begin{array}{l}\text { Exposure } \\
\text { measures } \\
\text { and } \\
\text { assessment }\end{array}$ & $\begin{array}{l}\text { Repeated } \\
\text { exposure } \\
\text { assessment }\end{array}$ & $\begin{array}{l}\text { Outcome } \\
\text { measures }\end{array}$ & $\begin{array}{l}\text { Blinding of } \\
\text { outcome } \\
\text { assessors }\end{array}$ & $\begin{array}{l}\text { Follow-up } \\
\text { rate }\end{array}$ & $\begin{array}{l}\text { Statistical } \\
\text { analyses }\end{array}$ & \\
\hline Tang et al. (125) & & & & & & & & & & & & ? & + & + & Good \\
\hline Before and after study & $\begin{array}{l}\text { Research } \\
\text { question }\end{array}$ & $\begin{array}{l}\text { Eligibility } \\
\text { criteria and } \\
\text { study } \\
\text { population }\end{array}$ & $\begin{array}{l}\text { The study } \\
\text { participants } \\
\text { representative } \\
\text { of clinical } \\
\text { populations of } \\
\text { interest }\end{array}$ & $\begin{array}{l}\text { All eligible } \\
\text { participants } \\
\text { enrolled }\end{array}$ & $\begin{array}{l}\text { Sample } \\
\text { size } \\
\text { justification }\end{array}$ & $\begin{array}{l}\text { Intervention } \\
\text { clearly } \\
\text { described }\end{array}$ & $\begin{array}{l}\text { Outcome } \\
\text { measures } \\
\text { clearly } \\
\text { described, } \\
\text { valid, and } \\
\text { reliable }\end{array}$ & $\begin{array}{l}\text { Blinding of } \\
\text { outcome } \\
\text { assessors }\end{array}$ & $\begin{array}{l}\text { Follow-up } \\
\text { rate }\end{array}$ & $\begin{array}{l}\text { Statistical } \\
\text { analyses }\end{array}$ & $\begin{array}{l}\text { Multiple } \\
\text { outcome } \\
\text { measures }\end{array}$ & $\begin{array}{l}\text { Group- } \\
\text { level } \\
\text { interventions } \\
\text { and } \\
\text { individual- } \\
\text { level } \\
\text { outcome } \\
\text { efforts }\end{array}$ & $\begin{array}{c}\text { No } \\
\text { question }\end{array}$ & $\begin{array}{c}\text { No } \\
\text { question }\end{array}$ & \\
\hline Hosomi et al. (126) & & & & & & & & & & & & $\begin{array}{c}\text { Not } \\
\text { applicable }\end{array}$ & - & - & Fair \\
\hline Hasan et al. (127) & & & & & & & & & & & & $\begin{array}{c}\text { Not } \\
\text { applicable }\end{array}$ & - & - & Poor \\
\hline Kobayashi et al. (128) & & & & & & & & & & & & $\begin{array}{c}\text { Not } \\
\text { applicable }\end{array}$ & - & - & Poor \\
\hline
\end{tabular}


indicates differing results among them. In most of the assessed studies, we observed slight variabilities in the RMT and MEP. Only the study by Hosomi et al. (126) observed statistically significant differences in $\operatorname{RMT}(P=0.035)$ and found a tendency of reduced ICF, SICI, and CSP prolongation when comparing measures of the affected hemisphere with control subjects. The decreases in ICF and SICI found in the study of Hosomi et al. (126) are likely more critical in their contrast with the findings of the study of Tang et al. (125). In assessing CE, several factors might explain intra-subject variability, including age $(130,131)$, sex (130), sleep deprivation (132), the severity of the disease (133), CNS drugs (i.e., anticonvulsants, antidepressants, benzodiazepines, and opioids) (134), and structural damage $(65,112)$. Hence, we should interpret the nature of the small variability in MT and MEP with parsimony since several reasons may explain these findings, as shown below.

One possible factor that could explain this slight difference in MT and MEP would be the severity of motor sequela, which varied from mild to moderate, which might influence the $\mathrm{CE}$ parameters by TMS compared to controls. This hypothesis is plausible because none of the four studies quantitatively sorted motor impairments. The studies of Tang et al. (125), Hosomi et al. (126), and Hasan et al. (127) mentioned that most of the patients had mild to moderate motor impairments or they showed rapid recovery after clinical discharge, during outpatient follow-up. Nonetheless, this is descriptive and does not permit an estimate of the severity of motor disability. Another factor influencing CE parameters is the time elapsed between the stroke and measurement acquisition. This information was found only in the study by Kobayashi et al. (128), which reported an average time of 19.7 months $(\mathrm{SD}=9)$ after stroke. Moreover, Hasan et al. (127) excluded individuals whose motor response was not identified during MT measurements and the MEP amplitude from the statistical analysis; thus, this could underestimate the real mean values of the cortical measures.

Conversely, the differences in the ICF and SICI between the studies of Hosomi et al. (126) and Tang et al. (125) can be explained in other ways. Although, there are no clear reasons for these mixed findings, these divergences may be associated with the clinical differences in patients and the methodological aspects of the studies. For example, in the study by Hosomi et al. (126), the paired stimulus intensity was defined from $80 \%$ of MT for the conditioning stimulus and $120 \%$ for the test stimulus. The ISI was $2-4 \mathrm{~ms}$ in SICI and 10 and $15 \mathrm{~ms}$ in ICF. In contrast, Tang et al. (125) established intervals of $3,5,7,10,15$, and $20 \mathrm{~ms}$ in the assessment of the ICI and facilitation. They used a conditioning stimulus at $70 \%$ of MT and $125 \%$ of this threshold for the test stimulus. Even though, it is not possible to quantify these differences in CPSP patients, according to evidence from studies in healthy subjects, these measurement intervals and thresholds for paired stimulus testing may influence the results. This hypothesis is supported by the findings of $\mathrm{Du}$ et al. (135), who demonstrated the existence of a range of reliability in inhibition and facilitation applying ISIs of $1-500 \mathrm{~ms}$ and limited to ISIs of $1-3 \mathrm{~ms}$ and $12-21 \mathrm{~ms}$, respectively. However, the authors highlighted a high variability in the MEP amplitude among healthy individuals in the ISI windows in which facilitation and inhibition occurred. This variability may be associated with an individual response of unclear etiology, the effect of CNS drugs, or imprecision in the signal capture between stimuli. Furthermore, it has been shown that, in healthy subjects, paired stimulation protocol influenced the SICI value according to the intensity of the test stimulus (100-150\% to RMT) in different situations of muscle excitability (rest and isometric abduction at the evaluated and contralateral index finger). They concluded that, regardless of the state of muscle excitability, an intensity of $\sim 120 \%$ of RMT generated the greatest inhibition (136). Indeed, the intensities of the conditioned pulse could be associated with variations in the SICI and ICF measurements. SICI was more significant at a 3-ms ISI when a conditioning stimulus equivalent to $80 \%$ intensity of RMT was applied, whereas, ICF was more evident in ISIs of 7 and $13 \mathrm{~ms}$ after the application of an equivalent conditioning stimulus of $90 \%$ of the RMT (137).

Likewise, it is not possible to reject whether the disagreements in the TMS measurements present in the studies of Hosomi et al. (126) and Tang et al. (125) are related to the effect of CNS drugs. Firstly, it is important to mention that, among the four studies included in this review, only Tang et al. (125) interrupted CNS drugs 3 days before TMS evaluations. Specifically, they performed a washout period of 3 days for medications indicated for the treatment of neuropathic pain. However, the CE measures obtained must be interpreted with parsimony, considering that they were done in a neuroadaptive phase (51). For instance, different studies have reported that chronic antidepressant treatment can stimulate the upregulation of genes associated with BDNF (138) and induce BDNF expression (139), important in the process of long-term potentiation and synaptic reorganization (140). Additionally, after $\sim 2$ weeks of antidepressant treatment (141), an increase in hippocampal neurogenesis associated with their behavioral effects was observed (142), which depended on BDNF activity (143). Conversely, in the study by Hosomi et al. (126), the participants were continuously using the following medications: gabapentin (in 11 cases), tricyclic antidepressants (in 9 patients), benzodiazepines (in 6), carbamazepine (in 5), selective serotonin reuptake inhibitors (in 4), non-steroidal antiinflammatory drugs (in 4), mexiletine (in 2), pregabalin (in 1 ), zonisamide (in 1), and phenytoin (in 1 patient). Although, it was not possible to find information concerning the effects of CNS drugs on the different TMS measurements of patients with CPSP, the results of studies in healthy subjects show that several of these drugs are responsible for variations in cortical activity. A review by Ziemann et al. (134) found that sodium channel blockers, such as carbamazepine and phenytoin, increase MT. These drugs produce neuronal hyperpolarization with modulation of the cortico-cortical and corticospinal axons. The carbamazepine effect on MT was reaffirmed by Darmani et al. (144) after administration of a single oral dose. Similarly, medications such as gabapentin and benzodiazepines, used in a significant number of patients in the study of Hosomi et al. (126), have been shown to affect CSP prolongation $(145,146)$ and ICF decrease $(147,148)$. According to pharmacodynamic principles, this effect may be due to GABA synthesis and the positive modulation of GABA A receptors $(134,147,149)$. Like 
gabapentin and benzodiazepines, sertraline (a serotonin reuptake inhibitor) decreased ICF after a single oral dose of $100 \mathrm{mg}$. This effect was linked to the activation of 5-hydroxytryptamine 3 receptors (5-HT3Rs) at the cortical level, found in inhibitory interneurons, and related to indirect pyramidal cell inhibition $(150,151)$.

Although, the studies did not use a scale or score to stratify the degree of motor impairment, it is plausible that the severity of the motor "deficit" and sensorial alterations were the determining factors in the cortical adaptive mechanisms present in the facilitation and inhibition measurements. In the study by Hosomi et al. (126), subjects presented with mild to moderate motor impairments. Hence, the study found neurophysiological variations characteristic of chronic stroke (i.e., differences in the RMT between hemispheres). However, in the study by Tang et al. (125), patients presented with persistent sensory alterations and, in most cases, without motor impairment or with posterior motor recovery at follow-up. Additionally, they showed changes in cortical activity characterized by a decrease in intracortical inhibition. The authors defined this cortical phenomenon as being characteristic of central pain and possibly related to a dysfunction of the medial lemniscus pathway. Similar results have already been reported by Liepert et al. (152) in patients with thalamic lesions and hemihypesthesia. They did not find clinical or electrophysiological evidence of compromise in the central or peripheral motor system; however, in the affected hemisphere, they found a decrease in intracortical inhibition and an enhancement of intracortical facilitation. The authors postulated that this cortical behavior can be explained by sensory input inhibition or an excitation-limiting effect over the motor cortex.

In summary, cortical plasticity mechanisms may be related to the development and recovery of sensory-motor changes after central system injury. According to preclinical models of spinal cord injury, motor "deficits" were related to adaptive cortical changes consequential to the imbalance between the GABAergic inhibition mechanism (153) and cortical excitatory stimulus release (154). These changes likely are necessary to remap the injured brain region and could be associated with the onset of neuropathic pain (155). This excitatory response influences the expression of Nav 1.3-dependent sodium-voltage channels associated with increased sensitivity to stimuli and central pain development (156). Hence, the importance of the cortical reorganization process in pain pathophysiology has already been confirmed. A direct association between the degree of reorganization of the primary somatosensory cortex and the pain intensity in individuals with spinal cord injury and neuropathic pain has been reported (157). However, patients with spinal cord injury showed an analgesic response to different therapies (e.g., virtual walking techniques) independently of the spinal cord injury level (158). Therefore, these effects were associated with changes in somatosensory cortex organization (159). From this set of data, it is possible to suppose that there are sensory and motor manifestations consequent to the same structural lesions in the CNS, which concurs with specific adaptive cortical changes, but with different evolution and responses to therapeutic approaches due to a neuroplasticity state influenced by varying degrees of physiological, biological, and social factors $(131,160,161)$.

\section{FUTURE DIRECTIONS}

Specialized centers allied to therapeutic advancements, such as thrombolysis and thrombectomy, led to scientific advances in the acute clinical treatment of stroke (162). Although, this advancement is of inestimable relevance, considering that stroke is the second leading cause of death by chronic disease in the world (1), it is vitally important that our efforts turn to seeking biomarkers that can assist in diagnosis, prognosis, and response predictors in the course of rehabilitation. In this scenario, CE measurements can help in understanding neuroplasticity processes, fundamental in the neurorehabilitation of somatosensorial systems. Although, pharmacological treatment of chronic neuropathic pain has grown substantially, together with the criteria to define neuropathic pain conditions $(163,164)$, evidence-based treatments of CPSP remain scarce. Thus, central pain clinical management is done empirically, by indication of the specialist. The lack of adequate parameters to evaluate clinical response and the lack of neurofunctional parameters to assess the therapeutic course make it difficult to open new therapeutic avenues. Thus, this review provides data pointing out ways that may help in the evaluation and research planning to seek rational treatment. The current CPSP classification is based mainly on descriptors, signs, and areas of the body where pain symptoms are referred to topographically, combined with information on anatomical impairment (e.g., neuroimaging data, such as functional magnetic resonance imaging). Few studies have evaluated CPSP with a perspective that integrates neurophysiological parameters with clinical, somatosensory, cognitive, and emotional symptoms. It is assumed that substantial improvements in the treatment of chronic pain after stroke may come from coordinated strategies that can identify specific mechanisms, aligning them with a biopsychosocial approach according to the ACTTION-American Pain Society Taxonomy (AAPT), which includes the following dimensions: (1) essential diagnostic criteria (e.g., symptoms, signs, diagnostic tests, and chronic pain condition); (2) standard features (e.g., location, temporal qualities, descriptors, fatigue, and numbness); (3) medical comorbidities (e.g., major depression); (4) neurobiological, psychosocial, and functional consequences; and (5) neurobiological and psychological mechanisms, as well as risk and protective factors (i.e., central sensitization, descending pain inhibitory system dysfunction, and somatosensory amplification) (165). In this context, more studies are needed to better understand an integrative view of the interactions among the different variables of the clinical picture, including the injury location, the degree of motor impairment, and the duration of CPSP.

\section{LIMITATIONS}

We know that this review has important limitations due to the limited number of articles available and the critical heterogeneity 
between them, preventing definitive conclusions about TMS parameters as markers of the neuroplasticity involved in CPSP. Other important factors that could hinder the interpretation of cortical measures are the heterogeneity between the protocols used, inappropriate control over the impacts of drugs, the lack of data concerning the time of disease, and the severity of clinical symptoms. It is also important to mention that the studies did not have a control condition for stroke patients without pain and present a lack of correlation analyses between pain levels and CE measures. These factors make it difficult to detangle the stroke structural effect only vs. the changes leading to pain.

Despite these limitations, one needs to consider that this is an emerging research area that may significantly impact public health, given its relevance in advancing stroke patient rehabilitation. From this review, we have identified several aspects of the risk of bias, such as the small sample size and heterogeneity, which reduce the strength of our conclusions. Thus, we need more studies to clarify CE measurement properties as diagnostic and prognostic biomarkers to predict the therapeutic response of CPSP. Although, TMS may be a useful method to answer these questions, the results are preliminary. According to this, our review points out several methodological aspects to consider in future studies, such as the establishment of a better description of the clinical symptoms related to impairments of somatosensory systems, the time elapsed between stroke and CPSP assessment, the definition of CNS lesion extent by neuroimaging methods, and current use of drugs with active effects on the CNS. It is also important to have a detailed description of the methods used to measure CE parameters. Hence, longitudinal data are important to monitor the effects of multiple confounding variables that are not easily controlled among patients, such as genetic, clinical, and environmental characteristics. Finally, we need studies to understand the potential benefit of therapies used to mitigate symptoms, including pharmacological and non-pharmacological interventions, behavioral techniques, or physical rehabilitation, in isolation or associated with magnetic stimulation.

\section{CONCLUSIONS}

The results of this systematic review indicate a significant heterogeneity among the studies examined, which limits the establishment of definitive conclusions on CE parameters as a diagnostic measure, prognostic indicator, or surrogate biomarker

\section{REFERENCES}

1. Feigin VL, Abajobir AA, Abate KH, Abd-Allah F, Abdulle AM, Abera SF, et al. Global, regional, and national burden of neurological disorders during 1990-2015: a systematic analysis for the Global Burden of Disease Study 2015. Lancet Neurol. (2017) 16:877-97. doi: 10.1016/S1474-4422(17)30299-5

2. Lopez AD, Mathers CD, Ezzati M, Jamison DT, Murray CJ. Global and regional burden of disease and risk factors, 2001: systematic analysis of population health data. Lancet. (2006) 367:1747-57. doi: 10.1016/S0140-6736(06)68770-9 related to CPSP. Despite the limited number of studies that prevented us from conducting a meta-analysis, the dataset of this systematic review provides evidence to improve our understanding of the physiopathology of CPSP. Additionally, the studies examined provide support to construct a framework for diagnosis and to improve the methodological quality of future research on somatosensory sequelae after stroke. Furthermore, they offer a way to integrate dysfunctional neuroplasticity markers assessed indirectly by neurophysiological measures with their correlated clinical symptoms.

\section{DATA AVAILABILITY STATEMENT}

The original contributions presented in the study are included in the article/supplementary material, further inquiries can be directed to the corresponding author/s.

\section{AUTHOR CONTRIBUTIONS}

DB, MT, and WC conceived and designed the study, participated in the data collection, performed the statistical analysis, and coordinated and drafted the manuscript. IT and FF drafted the work or revised it critically for important intellectual content. All authors have agreed and approved the final version of this work.

\section{FUNDING}

The present research was supported by the following Brazilian funding agencies: (i) Committee for the Development of Higher Education Personnel-CAPES PROEX (DFAB scholarship grant); (ii) National Council for Scientific and Technological Development-CNPq (no. 420826/2018-1, grant to WC); and (iii) the Postgraduate Research Group at the Hospital de Clínicas de Porto Alegre-FIPE HCPA for logistic and material support.

\section{ACKNOWLEDGMENTS}

We would like to thank the Hospital de Clínicas de Porto Alegre Clinical Research Facility for their facility and personnel for support in this study. We thank the following Brazilian agencies for the financial support: Committee for the Development of Higher Education Personnel-CAPES and National Council for Scientific and Technological Development-CNPq.

3. Kessner SS, Schlemm E, Cheng B, Bingel U, Fiehler J, Gerloff $\mathrm{C}$, et al. Somatosensory deficits after ischemic stroke: time course and association with infarct location. Stroke. (2019) 50:1116-23. doi: 10.1161/STROKEAHA.118.023750

4. Donkor ES. Stroke in the 21(st) century: a snapshot of the burden, epidemiology, and quality of life. Stroke Res Treat. (2018) 2018:3238165. doi: 10.1155/2018/3238165

5. Raghavan P. Upper limb motor impairment after stroke. Phys Med Rehabil Clin N Am. (2015) 26:599-610. doi: 10.1016/j.pmr.2015. 06.008 
6. Seifert CL, Mallar Chakravarty M, Sprenger T. The complexities of pain after stroke-a review with a focus on central post-stroke pain. Panminerva Med. (2013) 55:1-10.

7. Treister AK, Hatch MN, Cramer SC, Chang EY. Demystifying poststroke pain: from etiology to treatment. PM R. (2017) 9:63-75. doi: 10.1016/j.pmrj.2016.05.015

8. Guédon A, Thiebaut JB, Benichi S, Mikol J, Moxham B, Plaisant O. Dejerine-Roussy syndrome: historical cases. Neurology. (2019) 93:6249. doi: 10.1212/WNL.0000000000008209

9. Krause T, Brunecker P, Pittl S, Taskin B, Laubisch D, Winter B, et al. Thalamic sensory strokes with and without pain: differences in lesion patterns in the ventral posterior thalamus. J Neurol Neurosurg Psychiatry. (2012) 83:77684. doi: 10.1136/jnnp-2011-301936

10. Sprenger T, Seifert CL, Valet M, Andreou AP, Foerschler A, Zimmer C, et al. Assessing the risk of central post-stroke pain of thalamic origin by lesion mapping. Brain. (2012) 135:2536-45. doi: 10.1093/brain/aws153

11. MacGowan DJ, Janal MN, Clark WC, Wharton RN, Lazar RM, Sacco RL, et al. Central poststroke pain and Wallenberg's lateral medullary infarction: frequency, character, and determinants in 63 patients. Neurology. (1997) 49:120-5. doi: 10.1212/WNL.49.1.120

12. Kim JS. Central post-stroke pain or paresthesia in lenticulo-capsular hemorrhages. Neurology. (2003) 61:679-82. doi: 10.1212/WNL.61. 5.679

13. Garcia-Larrea L. The posterior insular-opercular region and the search of a primary cortex for pain. Neurophysiol Clin Neurophysiol. (2012) 42:299313. doi: 10.1016/j.neucli.2012.06.001

14. Vestergaard K, Nielsen J, Andersen G, Ingeman-Nielsen M, ArendtNielsen L, Jensen TS. Sensory abnormalities in consecutive, unselected patients with central post-stroke pain. Pain. (1995) 61:177-86. doi: 10.1016/0304-3959(94)00140-A

15. Oh H, Seo W. A comprehensive review of central post-stroke pain. Pain Manag Nurs Off J Am Soc Pain Manag Nurses. (2015) 16:80418. doi: 10.1016/j.pmn.2015.03.002

16. Kumar B, Kalita J, Kumar G, Misra UK. Central poststroke pain: a review of pathophysiology and treatment. Anesth Analg. (2009) 108:164557. doi: 10.1213/ane.0b013e31819d644c

17. Jönsson A-C, Lindgren I, Hallström B, Norrving B, Lindgren A. Prevalence and intensity of pain after stroke: a population based study focusing on patients' perspectives. J Neurol Neurosurg Psychiatry. (2006) 77:5905. doi: 10.1136/jnnp.2005.079145

18. Andersen G, Vestergaard K, Ingeman-Nielsen $M$, Jensen TS. Incidence of central post-stroke pain. Pain. (1995) 61:18793. doi: 10.1016/0304-3959(94)00144-4

19. Nasreddine ZS, Saver JL. Pain after thalamic stroke: right diencephalic predominance and clinical features in 180 patients. Neurology. (1997) 48:1196-9. doi: 10.1212/WNL.48.5.1196

20. Kumar G, Soni CR. Central post-stroke pain: current evidence. J Neurol Sci. (2009) 284:10-7. doi: 10.1016/j.jns.2009.04.030

21. Klit H, Finnerup NB, Jensen TS. Defining post-stroke pain: diagnostic challenges - authors' reply. Lancet Neurol. (2010) 9:344-5. doi: 10.1016/S1474-4422(10)70073-9

22. Boivie J. Chapter 48 central post-stroke pain. In: Cervero F, Jensen T, editors. Pain. Elsevier (2006). p. 715-30. doi: 10.1016/S0072-9752(06) 80052-7

23. Bashir AH, Abdullahi A, Abba MA, Mukhtar NB. Central poststroke pain: its profile among stroke survivors in Kano, Nigeria. Behav Neurol. (2017) 2017:9318597. doi: 10.1155/2017/9318597

24. Kim JS. Post-stroke pain. Expert Rev Neurother. (2009) 9:711-21. doi: 10.1586/ern.09.19

25. Bogousslavsky J, Regli F, Uske A. Thalamic infarcts. Neurology. (1988) 38:837-48. doi: 10.1212/WNL.38.6.837

26. Kim JS, Choi-Kwon S. Sensory sequelae of medullary infarction differences between lateral and medial medullary syndrome. Stroke. (1999) 30:2697703. doi: $10.1161 / 01 . S T R .30 .12 .2697$

27. Finnerup NB, Haroutounian S, Kamerman P, Baron R, Bennett DLH, Bouhassira D, et al. Neuropathic pain: an updated grading system for research and clinical practice. Pain. (2016) 157:1599-606. doi: 10.1097/j.pain.0000000000000492
28. Klit H, Finnerup NB, Jensen TS. Central post-stroke pain: clinical characteristics, pathophysiology, and management. Lancet Neurol. (2009) 8:857-68. doi: 10.1016/S1474-4422(09)70176-0

29. Klit H, Hansen AP, Marcussen NS, Finnerup NB, Jensen TS. Early evoked pain or dysesthesia is a predictor of central poststroke pain. Pain. (2014) 155:2699-706. doi: 10.1016/j.pain.2014.09.037

30. Hansen AP, Marcussen NS, Klit H, Andersen G, Finnerup NB, Jensen TS. Pain following stroke: a prospective study. Eur J Pain. (2012) 16:112836. doi: 10.1002/j.1532-2149.2012.00123.x

31. Westlund KN. 8 - pain pathways: peripheral, spinal, ascending, descending pathways. In: Benzon HT, Rathmell JP, Wu CL, Turk DC, Argoff CE, Hurley RW, editors. 5th ed. Practical Management of Pain. Philadelphia: Mosby (2013). p. 87-98.e5. doi: 10.1016/B978-0-323-08340-9.00008-6

32. Head H, Holmes G. Sensory disturbances from cerebral lesions1. Brain. (1911) 34:102-254. doi: 10.1093/brain/34.2-3.102

33. Craig AD, Bowsher D, Tasker RR, Lenz FA, Dougherty PM, WiesenfeldHallin Z. A new version of the thalamic disinhibition hypothesis of central pain. Pain Forum. (1998) 7:1-28. doi: 10.1016/S1082-3174(98)70004-2

34. Boivie J, Leijon G, Johansson I. Central post-stroke pain-a study of the mechanisms through analyses of the sensory abnormalities. Pain. (1989) 37:173-85. doi: 10.1016/0304-3959(89)90128-0

35. Vartiainen N, Perchet C, Magnin M, Creac'h C, Convers P, Nighoghossian $\mathrm{N}$, et al. Thalamic pain: anatomical and physiological indices of prediction. Brain. (2016) 139:708-22. doi: 10.1093/brain/awv389

36. Krause T, Asseyer S, Taskin B, Flöel A, Witte A V., Mueller K, et al. The cortical signature of central poststroke pain: gray matter decreases in somatosensory, insular, and prefrontal cortices. Cereb Cortex. (2016) 26:80-8. doi: 10.1093/cercor/bhu177

37. Gritsch S, Bali KK, Kuner R, Vardeh D. Functional characterization of a mouse model for central post-stroke pain. Mol Pain. (2016) 12:111. doi: $10.1177 / 1744806916629049$

38. Kadono Y, Koguchi K, Okada K, Hosomi K, Hiraishi M, Ueguchi T, et al. Repetitive transcranial magnetic stimulation restores altered functional connectivity of central poststroke pain model monkeys. Sci Rep. (2021) 11:6126. doi: 10.1038/s41598-021-85409-w

39. Kuan Y-H, Shih H-C, Shyu B-C. Involvement of $\mathrm{P}(2) \mathrm{X}(7)$ receptors and BDNF in the pathogenesis of central poststroke pain. Adv Exp Med Biol. (2018) 1099:211-27. doi: 10.1007/978-981-13-1756-9_18

40. Li X, Feng Y, Gao F. Maladaptive reorganization in pain-related brain network contributing to the central post-stroke pain. Neuropsychiatry. (2019) 9:2186-97.

41. Kim JS. Pharmacological management of central post-stroke pain: a practical guide. CNS Drugs. (2014) 28:787-97. doi: 10.1007/s40263-014-0194-y

42. Pickering AE, Thornton SR, Love-Jones SJ, Steeds C, Patel NK. Analgesia in conjunction with normalisation of thermal sensation following deep brain stimulation for central post-stroke pain. Pain. (2009) 147:299304. doi: 10.1016/j.pain.2009.09.011

43. Xu X-M, Luo H, Rong B, Zheng X-M, Wang F, Zhang S-J, et al. Nonpharmacological therapies for central poststroke pain: a systematic review. Medicine. (2020) 99:e22611. doi: 10.1097/MD.0000000000022611

44. Badawy RAB, Loetscher T, Macdonell RAL, Brodtmann A. Cortical excitability and neurology: insights into the pathophysiology. Funct Neurol. (2012) 27:131-45.

45. Kobayashi M, Pascual-Leone A. Transcranial magnetic stimulation in neurology. Lancet Neurol. (2003) 2:14556. doi: 10.1016/S1474-4422(03)00321-1

46. Groppa S, Oliviero A, Eisen A, Quartarone A, Cohen LG, Mall V, et al. A practical guide to diagnostic transcranial magnetic stimulation: report of an IFCN committee. Clin Neurophysiol. (2012) 123:85882. doi: 10.1016/j.clinph.2012.01.010

47. Lefaucheur J-P. Transcranial magnetic stimulation. Handb Clin Neurol. (2019) 160:559-80. doi: 10.1016/B978-0-444-64032-1.00037-0

48. Terao Y, Ugawa Y. Basic mechanisms of TMS. J Clin Neurophysiol Off Publ Am Electroencephalogr Soc. (2002) 19:322-43. doi: 10.1097/00004691-200208000-00006

49. Rossini PM, Burke D, Chen R, Cohen LG, Daskalakis Z, Di Iorio R, et al. Non-invasive electrical and magnetic stimulation of the brain, spinal cord, roots and peripheral nerves: basic principles and procedures for routine 
clinical and research application. An updated report from an I.F.C.N. Committee. Clin Neurophysiol Off J Int Fed Clin Neurophysiol. (2015) 126:1071-107. doi: 10.1016/j.clinph.2015.02.001

50. Hodgkin AL, Huxley AF. A quantitative description of membrane current and its application to conduction and excitation in nerve. J Physiol. (1952) 117:500-44. doi: 10.1113/jphysiol.1952.sp004764

51. Caipa A, Alomar M, Bashir S. TMS as tool to investigate the effect of pharmacological medications on cortical plasticity. Eur Rev Med Pharmacol Sci. (2018) 22:844-52. doi: 10.26355/eurrev_201802_14321

52. Rossini PM, Berardelli A, Deuschl G, Hallett M, Maertens de Noordhout AM, Paulus W, et al. Applications of magnetic cortical stimulation. The International Federation of Clinical Neurophysiology. Electroencephalogr Clin Neurophysiol Suppl. (1999) 52:171-85.

53. Fuhr P, Agostino R, Hallett M. Spinal motor neuron excitability during the silent period after cortical stimulation. Electroencephalogr Clin Neurophysiol. (1991) 81:257-62. doi: 10.1016/0168-5597(91)90011-L

54. Fisher RJ, Nakamura Y, Bestmann S, Rothwell JC, Bostock H. Two phases of intracortical inhibition revealed by transcranial magnetic threshold tracking. Exp brain Res. (2002) 143:240-8. doi: 10.1007/s00221-001-0988-2

55. Hanajima R, Ugawa Y, Terao Y, Sakai K, Furubayashi T, Machii $\mathrm{K}$, et al. Paired-pulse magnetic stimulation of the human motor cortex: differences among I waves. J Physiol. (1998) 509(Pt. 2):60718. doi: 10.1111/j.1469-7793.1998.607bn.x

56. Di Lazzaro V, Pilato F, Dileone M, Profice P, Ranieri F, Ricci V, et al. Segregating two inhibitory circuits in human motor cortex at the level of GABAA receptor subtypes: a TMS study. Clin Neurophysiol Off $J$ Int Fed Clin Neurophysiol. (2007) 118:2207-14. doi: 10.1016/j.clinph.2007. 07.005

57. Oliveri M, Caltagirone C, Filippi MM, Traversa R, Cicinelli P, Pasqualetti $\mathrm{P}$, et al. Paired transcranial magnetic stimulation protocols reveal a pattern of inhibition and facilitation in the human parietal cortex. J Physiol. (2000) 529(Pt. 2):461-8. doi: 10.1111/j.1469-7793.2000.00461.x

58. Kujirai T, Caramia MD, Rothwell JC, Day BL, Thompson PD, Ferbert A, et al. Corticocortical inhibition in human motor cortex. J Physiol. (1993) 471:501-19. doi: 10.1113/jphysiol.1993.sp019912

59. Di Lazzaro V, Oliviero A, Profice P, Pennisi MA, Di Giovanni S, Zito G, et al. Muscarinic receptor blockade has differential effects on the excitability of intracortical circuits in the human motor cortex. Exp brain Res. (2000) 135:455-61. doi: 10.1007/s002210000543

60. Di Lazzaro V, Oliviero A, Saturno E, Dileone M, Pilato F, Nardone R, et al. Effects of lorazepam on short latency afferent inhibition and short latency intracortical inhibition in humans. J Physiol. (2005) 564:6618. doi: 10.1113/jphysiol.2004.061747

61. Ferbert A, Priori A, Rothwell JC, Day BL, Colebatch JG, Marsden CD. Interhemispheric inhibition of the human motor cortex. J Physiol. (1992) 453:525-46. doi: 10.1113/jphysiol.1992.sp019243

62. Ugawa Y, Uesaka Y, Terao Y, Hanajima R, Kanazawa I. Magnetic stimulation over the cerebellum in humans. Ann Neurol. (1995) 37:70313. doi: $10.1002 /$ ana. 410370603

63. Pennisi G, Ferri R, Cantone M, Lanza G, Pennisi M, Vinciguerra L, et al. A review of transcranial magnetic stimulation in vascular dementia. Dement Geriatr Cogn Disord. (2011) 31:71-80. doi: 10.1159/000322798

64. Granovsky Y, Sprecher E, Sinai A. Motor corticospinal excitability: a novel facet of pain modulation? Pain reports. (2019) 4:e725. doi: 10.1097/PR9.0000000000000725

65. Lefaucheur JP, Drouot X, Ménard-Lefaucheur I, Keravel Y, Nguyen JP. Motor cortex rTMS restores defective intracortical inhibition in chronic neuropathic pain. Neurology. (2006) 67:1568-74. doi: 10.1212/01.wnl.0000242731.10074.3c

66. Chen R, Cros D, Curra A, Di Lazzaro V, Lefaucheur J-P, Magistris MR, et al. The clinical diagnostic utility of transcranial magnetic stimulation: report of an IFCN committee. Clin Neurophysiol. (2008) 119:50432. doi: 10.1016/j.clinph.2007.10.014

67. Mills KR, Nithi KA. Corticomotor threshold to magnetic stimulation: normal values and repeatability. Muscle Nerve. (1997) 20:570-6. doi: 10.1002/ (SICI) 1097-4598(199705)20:5\&lt;570::AID-MUS5\&gt;3.0.CO;2-6

68. Julkunen P, Könönen M, Määttä S, Tarkka IM, Hiekkala SH, Säisänen $\mathrm{L}$, et al. Longitudinal study on modulated corticospinal excitability throughout recovery in supratentorial stroke. Neurosci Lett. (2016) 617:8893. doi: 10.1016/j.neulet.2016.02.014

69. Manganotti P, Acler M, Zanette GP, Smania N, Fiaschi A. Motor cortical disinhibition during early and late recovery after stroke. Neurorehabil Neural Repair. (2008) 22:396-403. doi: 10.1177/1545968307313505

70. Manganotti P, Patuzzo S, Cortese F, Palermo A, Smania N, Fiaschi A. Motor disinhibition in affected and unaffected hemisphere in the early period of recovery after stroke. Clin Neurophysiol. (2002) 113:936-43. doi: 10.1016/S1388-2457(02)00 062-7

71. Fridman EA, Hanakawa T, Chung M, Hummel F, Leiguarda RC, Cohen LG. Reorganization of the human ipsilesional premotor cortex after stroke. Brain. (2004) 127:747-58. doi: 10.1093/brain/awh082

72. Pennisi G, Alagona G, Rapisarda G, Nicoletti F, Costanzo E, Ferri $\mathrm{R}$, et al. Transcranial magnetic stimulation after pure motor stroke. Clin Neurophysiol Off J Int Fed Clin Neurophysiol. (2002) 113:153643. doi: 10.1016/S1388-2457(02)00255-9

73. Foltys H, Krings T, Meister IG, Sparing R, Boroojerdi B, Thron A, et al. Motor representation in patients rapidly recovering after stroke: a functional magnetic resonance imaging and transcranial magnetic stimulation study. Clin Neurophysiol Off J Int Fed Clin Neurophysiol. (2003) 114:240415. doi: 10.1016/S1388-2457(03)00263-3

74. Cicinelli P, Traversa R, Rossini PM. Post-stroke reorganization of brain motor output to the hand: a 2-4 month follow-up with focal magnetic transcranial stimulation. Electroencephalogr Clin Neurophysiol - Electromyogr Mot Control. (1997) 105:43850. doi: 10.1016/S0924-980X(97)00052-0

75. Cicinelli P, Pasqualetti P, Zaccagnini M, Traversa R, Oliveri M, Rossini PM. Interhemispheric asymmetries of motor cortex excitability in the postacute stroke stage: a paired-pulse transcranial magnetic stimulation study. Stroke. (2003) 34:2653-8. doi: 10.1161/01.STR.0000092122.96722.72

76. Byblow WD, Stinear CM, Barber PA, Petoe MA, Ackerley SJ. Proportional recovery after stroke depends on corticomotor integrity. Ann Neurol. (2015) 78:848-59. doi: 10.1002/ana.24472

77. Lindner M, Heine S, Haastert K, Garde N, Fokuhl J, Linsmeier F, et al. Sequential myelin protein expression during remyelination reveals fast and efficient repair after central nervous system demyelination. Neuropathol Appl Neurobiol. (2008) 34:105-14. doi: 10.1111/j.1365-2990.2007.00879.x

78. Delvaux V, Alagona G, Gérard P, De Pasqua V, Pennisi G, de Noordhout AM. Post-stroke reorganization of hand motor area: a 1year prospective follow-up with focal transcranial magnetic stimulation. Clin Neurophysiol Off J Int Fed Clin Neurophysiol. (2003) 114:121725. doi: 10.1016/S1388-2457(03)00070-1

79. Liepert J, Restemeyer C, Kucinski T, Zittel S, Weiller C. Motor strokes: the lesion location determines motor excitability changes. Stroke. (2005) 36:2648-53. doi: 10.1161/01.STR.0000189629.10603.02

80. Talelli P, Greenwood RJ, Rothwell JC. Arm function after stroke: neurophysiological correlates and recovery mechanisms assessed by transcranial magnetic stimulation. Clin Neurophysiol Off J Int Fed Clin Neurophysiol. (2006) 117:1641-59. doi: 10.1016/j.clinph.2006.01.016

81. Di Lazzaro V, Pilato F, Dileone M, Profice P, Capone F, Ranieri F, et al. Modulating cortical excitability in acute stroke: a repetitive TMS study. Clin Neurophysiol Off J Int Fed Clin Neurophysiol. (2008) 119:71523. doi: 10.1016/j.clinph.2007.11.049

82. Traversa R, Cicinelli P, Oliveri M, Giuseppina Palmieri M, Maddalena Filippi M, Pasqualetti P, et al. Neurophysiological follow-up of motor cortical output in stroke patients. Clin Neurophysiol. (2000) 111:1695703. doi: 10.1016/S1388-2457(00)00373-4

83. Liepert J, Graef S, Uhde I, Leidner O, Weiller C. Training-induced changes of motor cortex representations in stroke patients. Acta Neurol Scand. (2000) 101:321-6. doi: 10.1034/j.1600-0404.2000.90337a.x

84. Pennisi G, Rapisarda G, Bella R, Calabrese V, Maertens De Noordhout A, Delwaide PJ. Absence of response to early transcranial magnetic stimulation in ischemic stroke patients: prognostic value for hand motor recovery. Stroke. (1999) 30:2666-70. doi: 10.1161/01.STR.30.12.2666

85. Harris-Love M. Transcranial magnetic stimulation for the prediction and enhancement of rehabilitation treatment effects. J Neurol Phys Ther. (2012) 36:87-93. doi: 10.1097/NPT.0b013e3182564d26 
86. Koski L, Mernar TJ, Dobkin BH. Immediate and long-term changes in corticomotor output in response to rehabilitation: correlation with functional improvements in chronic stroke. Neurorehabil Neural Repair. (2004) 18:230-49. doi: 10.1177/1545968304269210

87. Liepert J, Storch P, Fritsch A, Weiller C. Motor cortex disinhibition in acute stroke. Clin Neurophysiol. (2000) 111:6716. doi: 10.1016/S1388-2457(99)00312-0

88. Huynh W, Vucic S, Krishnan A V, Lin CS-Y, Kiernan MC. Exploring the evolution of cortical excitability following acute stroke. Neurorehabil Neural Repair. (2016) 30:244-57. doi: 10.1177/1545968315593804

89. Shimizu T, Hosaki A, Hino T, Sato M, Komori T, Hirai S, et al. Motor cortical disinhibition in the unaffected hemisphere after unilateral cortical stroke. Brain. (2002) 125:1896-907. doi: 10.1093/brain/awf183

90. Netz J, Lammers T, Hömberg V. Reorganization of motor output in the non-affected hemisphere after stroke. Brain. (1997) 120(Pt. 9):157986. doi: 10.1093/brain/120.9.1579

91. Traversa R, Cicinelli P, Pasqualetti P, Filippi M, Rossini PM. Follow-up of interhemispheric differences of motor evoked potentials from the 'affected' and 'unaffected' hemispheres in human stroke. Brain Res. (1998) 803:18. doi: 10.1016/S0006-8993(98)00505-8

92. Niehaus L, Bajbouj M, Meyer B-U. Chapter 17 impact of interhemispheric inhibition on excitability of the non-lesioned motor cortex after acute stroke. In: Paulus W, Tergau F, Nitsche MA, Rothwell JG, Ziemann U, Hallett M, editors. Transcranial Magnetic Stimulation and Transcranial Direct Current Stimulation. Elsevier (2003). p. 181-6. doi: 10.1016/S1567-424X(09)70220-X

93. Liepert J. Motor cortex excitability in stroke before and after constraintinduced movement therapy. Cogn Behav Neurol Off J Soc Behav Cogn Neurol. (2006) 19:41-7. doi: 10.1097/00146965-200603000-00005

94. Julkunen $P$, Määttä S, Säisänen L, Kallioniemi E, Könönen $M$, Jäkälä $P$, et al. Functional and structural cortical characteristics after restricted focal motor cortical infarction evaluated at chronic stage - indications from a preliminary study. Clin Neurophysiol Off J Int Fed Clin Neurophysiol. (2016) 127:2775-84. doi: 10.1016/j.clinph.2016.05.013

95. McDonnell MN, Stinear CM. TMS measures of motor cortex function after stroke: a meta-analysis. Brain Stimul. (2017) 10:721-34. doi: 10.1016/j.brs.2017.03.008

96. Malcolm MP, Vaughn HN, Greene DP. Inhibitory and excitatory motor cortex dysfunction persists in the chronic poststroke recovery phase. $J$ Clin Neurophysiol Off Publ Am Electroencephalogr Soc. (2015) 32:2516. doi: 10.1097/WNP.0000000000000143

97. Seo HY, Kim G-W, Won YH, Park S-H, Seo J-H, Ko M-H. Changes in intracortical excitability of affected and unaffected hemispheres after stroke evaluated by paired-pulse transcranial magnetic stimulation. Ann Rehabil Med. (2018) 42:495-501. doi: 10.5535/arm.2018.42.4.495

98. Liepert J. Chapter 37 TMS in stroke. In: Paulus W, Tergau F, Nitsche MA, Rothwell JG, Ziemann U, Hallett M, editors. Transcranial Magnetic Stimulation Transcranial Direct Current Stimulation. Elsevier (2003). p. 368-80. doi: 10.1016/S1567-424X(09)70240-5

99. Classen J, Schnitzler A, Binkofski F, Werhahn KJ, Kim YS, Kessler KR, et al. The motor syndrome associated with exaggerated inhibition within the primary motor cortex of patients with hemiparetic. Brain. (1997) 120(Pt. 4):605-19. doi: 10.1093/brain/120.4.605

100. Ahonen J-P, Jehkonen M, Dastidar P, Molnár G, Häkkinen V. Cortical silent period evoked by transcranial magnetic stimulation in ischemic stroke. Electroencephalogr Clin Neurophysiol Mot Control. (1998) 109:2249. doi: 10.1016/S0924-980X(98)00014-9

101. Van Kuijk AA, Pasman JW, Geurts ACH, Hendricks HT. How salient is the silent period? The role of the silent period in the prognosis of upper extremity motor recovery after severe stroke. J Clin Neurophysiol. (2005) 22:10-24. doi: 10.1097/01.WNP.0000150975.83249.71

102. Schnitzler A, Benecke R. The silent period after transcranial magnetic stimulation is of exclusive cortical origin: evidence from isolated cortical ischemic lesions in man. Neurosci Lett. (1994) 180:41-5. doi: 10.1016/0304-3940(94)90909-1

103. Byrnes ML, Thickbroom GW, Phillips BA, Mastaglia FL. Long-term changes in motor cortical organisation after recovery from subcortical stroke. Brain Res. (2001) 889:278-87. doi: 10.1016/S0006-8993(00)03089-4
104. Oozumi T, Ito $\mathrm{Y}$, Tsuji S, Murai $\mathrm{Y}$. Inhibitory period following motor potentials evoked by magnetic cortical stimulation. Electroencephalogr Clin Neurophysiol Potentials Sect. (1992) 85:273-9. doi: 10.1016/0168-5597(92)90116-S

105. Catano A, Houa M, Noël P. Magnetic transcranial stimulation: dissociation of excitatory and inhibitory mechanisms in acute strokes. Electroencephalogr Clin Neurophysiol - Electromyogr Mot Control. (1997) 105:29-36. doi: 10.1016/S0924-980X(96)96515-7

106. Dubé JA, Mercier C. Effect of pain and pain expectation on primary motor cortex excitability. Clin Neurophysiol Off J Int Fed Clin Neurophysiol. (2011) 122:2318-23. doi: 10.1016/j.clinph.2011.03.026

107. Salo KS-T, Vaalto SMI, Koponen LM, Nieminen JO, Ilmoniemi RJ. The effect of experimental pain on short-interval intracortical inhibition with multilocus transcranial magnetic stimulation. Exp brain Res. (2019) 237:150310. doi: 10.1007/s00221-019-05502-5

108. Martel M, Harvey M-P, Houde F, Balg F, Goffaux P, Léonard G. Unravelling the effect of experimental pain on the corticomotor system using transcranial magnetic stimulation and electroencephalography. Exp brain Res. (2017) 235:1223-31. doi: 10.1007/s00221-017-4880-0

109. Burns E, Chipchase LS, Schabrun SM. Primary sensory and motor cortex function in response to acute muscle pain: a systematic review and metaanalysis. Eur J Pain. (2016) 20:1203-13. doi: 10.1002/ejp.859

110. Schwenkreis P, Maier C, Tegenthoff M. Chapter 40 fluctuations of motor cortex excitability in pain syndromes. In: Paulus W, Tergau F, Nitsche MA, Rothwell JG, Ziemann U, Hallett M, editors. Transcranial Magnetic Stimulation Transcranial Direct Current Stimulation. Elsevier (2003). p. 394-9. doi: 10.1016/S1567-424X(09)70243-0

111. Botelho LM, Morales-Quezada L, Rozisky JR, Brietzke AP, Torres ILS, Deitos A, et al. A framework for understanding the relationship between descending pain modulation, motor corticospinal, and neuroplasticity regulation systems in chronic myofascial pain. Front Hum Neurosci. (2016) 10:308. doi: 10.3389/fnhum.2016.00308

112. Caumo W, Deitos A, Carvalho S, Leite J, Carvalho F, Dussán-Sarria JA, et al. Motor cortex excitability and bdnf levels in chronic musculoskeletal pain according to structural pathology. Front Hum Neurosci. (2016) 10:357. doi: 10.3389/fnhum.2016.00357

113. Lei K, Kunnel A, Metzger-Smith V, Golshan S, Javors J, Wei J, et al. Diminished corticomotor excitability in Gulf War Illness related chronic pain symptoms; evidence from TMS study. Sci Rep. (2020) 10:18520. doi: 10.1038/s41598-020-75006-8

114. Salerno A, Thomas E, Olive P, Blotman F, Picot MC, Georgesco M. Motor cortical dysfunction disclosed by single and double magnetic stimulation in patients with fibromyalgia. Clin Neurophysiol Off J Int Fed Clin Neurophysiol. (2000) 111:994-1001. doi: 10.1016/S1388-2457(00)00267-4

115. Schabrun SM, Christensen SW, Mrachacz-Kersting N, GravenNielsen T. Motor cortex reorganization and impaired function in the transition to sustained muscle pain. Cereb Cortex. (2016) 26:1878-90. doi: 10.1093/cercor/bhu319

116. Schwenkreis P, Scherens A, Rönnau A-K, Höffken O, Tegenthoff M, Maier C. Cortical disinhibition occurs in chronic neuropathic, but not in chronic nociceptive pain. BMC Neurosci. (2010) 11:73. doi: 10.1186/1471-2202-11-73

117. Schabrun SM, Hodges PW. Muscle pain differentially modulates short interval intracortical inhibition and intracortical facilitation in primary motor cortex. J pain. (2012) 13:187-94. doi: 10.1016/j.jpain.2011. 10.013

118. Parker RS, Lewis GN, Rice DA, McNair PJ. Is motor cortical excitability altered in people with chronic pain? A systematic review and meta-analysis. Brain Stimul. (2016) 9:488-500. doi: 10.1016/j.brs.2016.03.020

119. Canavero S, Bonicalzi V. The neurochemistry of central pain: evidence from clinical studies, hypothesis and therapeutic implications. Pain. (1998) 74:109-14. doi: 10.1016/S0304-3959(97)00089-4

120. Daskalakis ZJ, Paradiso GO, Christensen BK, Fitzgerald PB, Gunraj C, Chen R. Exploring the connectivity between the cerebellum and motor cortex in humans. J Physiol. (2004) 557:689-700. doi: 10.1113/jphysiol.2003.059808

121. Na J, Kakei S, Shinoda Y. Cerebellar input to corticothalamic neurons in layers V and VI in the motor cortex. Neurosci Res. (1997) 28:7791. doi: 10.1016/S0168-0102(97)00031-X 
122. Bank PJM, Peper CE, Marinus J, Beek PJ, van Hilten JJ. Motor consequences of experimentally induced limb pain: a systematic review. Eur J Pain. (2013) 17:145-57. doi: 10.1002/j.1532-2149.2012.00186.x

123. Price DD. Psychological and neural mechanisms of the affective dimension of pain. Science. (2000) 288:1769-72. doi: 10.1126/science.288.5472.1769

124. Coombes SA, Misra G. Pain and motor processing in the human cerebellum. Pain. (2016) 157:117-27. doi: 10.1097/j.pain.0000000000000337

125. Tang S-C, Lee LJ-H, Jeng J-S, Hsieh S-T, Chiang M-C, Yeh S$\mathrm{J}$, et al. Pathophysiology of central poststroke pain: motor cortex disinhibition and its clinical and sensory correlates. Stroke. (2019) 50:28517. doi: 10.1161/STROKEAHA.119.025692

126. Hosomi K, Kishima H, Oshino S, Hirata M, Tani N, Maruo T, et al. Cortical excitability changes after high-frequency repetitive transcranial magnetic stimulation for central poststroke pain. Pain. (2013) 154:13527. doi: 10.1016/j.pain.2013.04.017

127. Hasan M, Whiteley J, Bresnahan R, MacIver K, Sacco P, Das K, et al. Somatosensory change and pain relief induced by repetitive transcranial magnetic stimulation in patients with central poststroke pain. Neuromodulation. (2014) 17:731-6; discussion 736. doi: 10.1111/ner.12198

128. Kobayashi M, Fujimaki T, Mihara B, Ohira T. Repetitive transcranial magnetic stimulation once a week induces sustainable longterm relief of central poststroke pain. Neuromodulation. (2015) 18:249-54. doi: 10.1111/ner.12301

129. Moher D, Liberati A, Tetzlaff J, Altman DG. Preferred reporting items for systematic reviews and meta-analyses: the PRISMA statement. PLoS Med. (2009) 6:e1000097. doi: 10.1371/journal.pmed.1000097

130. Corp DT, Bereznicki HGK, Clark GM, Youssef GJ, Fried PJ, Jannati A, et al. Large-scale analysis of interindividual variability in theta-burst stimulation data: results from the 'Big TMS Data Collaboration. Brain Stimul. (2020) 13:1476-88. doi: 10.1016/j.brs.2020.07.018

131. Saldanha JS, Zortea M, Torres IL da S, Fregni F, Caumo W. Age as a mediator of tDCS effects on pain: an integrative systematic review and meta-analysis. Front Hum Neurosci. (2020) 14:568306. doi: 10.3389/fnhum.2020.568306

132. Fountain NB. Transcranial magnetic stimulation and sleep deprivation as experimental tools: when sleep deprivation is too exciting. Epilepsy Curr. (2007) 7:151-2. doi: 10.1111/j.1535-7511.2007.00174.x

133. Jodoin M, Rouleau DM, Bellemare A, Provost C, Larson-Dupuis C, Sandman É, et al. Moderate to severe acute pain disturbs motor cortex intracortical inhibition and facilitation in orthopedic trauma patients: a TMS study. PLoS ONE. (2020) 15:e0226452. doi: 10.1371/journal.pone.0226452

134. Ziemann U, Reis J, Schwenkreis P, Rosanova M, Strafella A, Badawy R, et al. TMS and drugs revisited 2014. Clin Neurophysiol Off J Int Fed Clin Neurophysiol. (2015) 126:1847-68. doi: 10.1016/j.clinph.2014.08.028

135. Du X, Summerfelt A, Chiappelli J, Holcomb HH, Hong LE. Individualized brain inhibition and excitation profile in response to paired-pulse TMS. J Mot Behav. (2014) 46:39-48. doi: 10.1080/00222895.2013.850401

136. Garry MI, Thomson RHS. The effect of test TMS intensity on short-interval intracortical inhibition in different excitability states. Exp brain Res. (2009) 193:267-74. doi: 10.1007/s00221-008-1620-5

137. Säisänen L, Julkunen P, Niskanen E, Hukkanen T, Mervaala E, Karhu J, et al. Short- and intermediate-interval cortical inhibition and facilitation assessed by navigated transcranial magnetic stimulation. J Neurosci Methods. (2011) 195:241-8. doi: 10.1016/j.jneumeth.2010.11.022

138. Alme MN, Wibrand K, Dagestad G, Bramham CR. Chronic fluoxetine treatment induces brain region-specific upregulation of genes associated with BDNF-induced long-term potentiation. Neural Plast. (2007) 2007:26496. doi: 10.1155/2007/26496

139. Casarotto PC, Girych M, Fred SM, Kovaleva V, Moliner R, Enkavi G, et al. Antidepressant drugs act by directly binding to TRKB neurotrophin receptors. Cell. (2021) 184:1299-1313.e19. doi: 10.1016/j.cell.2021.01.034

140. Bramham CR, Messaoudi E. BDNF function in adult synaptic plasticity: the synaptic consolidation hypothesis. Prog Neurobiol. (2005) 76:99125. doi: 10.1016/j.pneurobio.2005.06.003

141. Malberg JE, Eisch AJ, Nestler EJ, Duman RS. Chronic antidepressant treatment increases neurogenesis in adult rat hippocampus. J Neurosci. (2000) 20:9104-10. doi: 10.1523/JNEUROSCI.20-24-09104.2000
142. Santarelli L, Saxe M, Gross C, Surget A, Battaglia F, Dulawa S, et al. Requirement of hippocampal neurogenesis for the behavioral effects of antidepressants. Science. (2003) 301:805-9. doi: 10.1126/science.1083328

143. Sairanen M, Lucas G, Ernfors P, Castrén M, Castrén E. Brainderived neurotrophic factor and antidepressant drugs have different but coordinated effects on neuronal turnover, proliferation, and survival in the adult dentate gyrus. J Neurosci. (2005) 25:1089-94. doi: 10.1523/JNEUROSCI.3741-04.2005

144. Darmani G, Bergmann TO, Zipser C, Baur D, Müller-Dahlhaus F, Ziemann U. Effects of antiepileptic drugs on cortical excitability in humans: a TMS-EMG and TMS-EEG study. Hum Brain Mapp. (2019) 40:127689. doi: $10.1002 / \mathrm{hbm} .24448$

145. Kimiskidis VK, Papagiannopoulos S, Kazis DA, Sotirakoglou K, Vasiliadis G, Zara F, et al. Lorazepam-induced effects on silent period and corticomotor excitability. Exp brain Res. (2006) 173:603-11. doi: 10.1007/s00221-006-0402-1

146. Rizzo V, Quartarone A, Bagnato S, Battaglia F, Majorana G, Girlanda P. Modification of cortical excitability induced by gabapentin: a study by transcranial magnetic stimulation. Neurol Sci Off J Ital Neurol Soc Ital Soc Clin Neurophysiol. (2001) 22:229-32. doi: 10.1007/s100720100002

147. Ziemann U, Lönnecker S, Steinhoff BJ, Paulus W. Effects of antiepileptic drugs on motor cortex excitability in humans: a transcranial magnetic stimulation study. Ann Neurol. (1996) 40:367-78. doi: 10.1002/ana.410400306

148. Mohammadi B, Krampfl K, Petri S, Bogdanova D, Kossev A, Bufler J, et al. Selective and non-selective benzodiazepine agonists have different effects on motor cortex excitability. Muscle Nerve. (2006) 33:77884. doi: $10.1002 /$ mus.20531

149. Ziemann U, Lönnecker S, Steinhoff BJ, Paulus W. The effect of lorazepam on the motor cortical excitability in man. Exp brain Res. (1996) 109:12735. doi: $10.1007 / \mathrm{BF} 00228633$

150. Ilic T V, Korchounov A, Ziemann U. Complex modulation of human motor cortex excitability by the specific serotonin re-uptake inhibitor sertraline. Neurosci Lett. (2002) 319:116-20. doi: 10.1016/S0304-3940(01)02 563-0

151. Roerig B, Katz LC. Modulation of intrinsic circuits by serotonin 5-HT3 receptors in developing ferret visual cortex. J Neurosci. (1997) 17:832438. doi: 10.1523/JNEUROSCI.17-21-08324.1997

152. Liepert J, Restemeyer C, Münchau A, Weiller C. Motor cortex excitability after thalamic infarction. Clin Neurophysiol Off J Int Fed Clin Neurophysiol. (2005) 116:1621-7. doi: 10.1016/j.clinph.2005. 03.002

153. Dougherty KJ, Hochman S. Spinal cord injury causes plasticity in a subpopulation of lamina I GABAergic interneurons. J Neurophysiol. (2008) 100:212-23. doi: 10.1152/jn.01104.2007

154. Endo T, Spenger C, Tominaga T, Brené S, Olson L. Cortical sensory map rearrangement after spinal cord injury: fMRI responses linked to Nogo signalling. Brain. (2007) 130:2951-61. doi: 10.1093/brain/ awm 237

155. Flor H, Elbert T, Knecht S, Wienbruch C, Pantev C, Birbaumer N, et al. Phantom-limb pain as a perceptual correlate of cortical reorganization following arm amputation. Nature. (1995) 375:482-4. doi: 10.1038/375 482a0

156. Hains BC, Saab CY, Waxman SG. Changes in electrophysiological properties and sodium channel Nav1.3 expression in thalamic neurons after spinal cord injury. Brain. (2005) 128:2359-71. doi: 10.1093/brain/ awh623

157. Wrigley PJ, Press SR, Gustin SM, Macefield VG, Gandevia SC, Cousins MJ, et al. Neuropathic pain and primary somatosensory cortex reorganization following spinal cord injury. Pain. (2009) 141:52-9. doi: 10.1016/j.pain.2008.10.007

158. Moseley LG. Using visual illusion to reduce at-level neuropathic pain in paraplegia. Pain. (2007) 130:294-8. doi: 10.1016/j.pain.2007.01.007

159. Maihöfner C, Handwerker HO, Neundörfer B, Birklein F. Cortical reorganization during recovery from complex regional pain syndrome. Neurology. (2004) 63:693-701. doi: 10.1212/01.WNL.0000134661.46658.B0 
160. Stoetzner CR, Pettibone JR, Berke JD. State-dependent plasticity of the corticostriatal pathway. Neuroscience. (2010) 165:1013-8. doi: 10.1016/j.neuroscience.2009. 11.031

161. Meyers EC, Kasliwal N, Solorzano BR, Lai E, Bendale G, Berry A, et al. Enhancing plasticity in central networks improves motor and sensory recovery after nerve damage. Nat Commun. (2019) 10:5782. doi: 10.1038/s41467-01913695-0

162. Powers WJ, Rabinstein AA, Ackerson T, Adeoye OM, Bambakidis $\mathrm{NC}$, Becker K, et al. Guidelines for the early management of patients with acute ischemic stroke: 2019 update to the 2018 guidelines for the early management of acute ischemic stroke: a guideline for healthcare professionals from the American Heart Association/American Stroke. Stroke. (2019) 50:e344-418. doi: 10.1161/STR.0000000000 000211

163. Schlereth T. Guideline "diagnosis and non interventional therapy of neuropathic pain" of the German Society of Neurology (deutsche Gesellschaft für Neurologie). Neurol Res Pract. (2020) 2:16. doi: 10.1186/s42466-020-00063-3

164. Cavalli E, Mammana S, Nicoletti F, Bramanti P, Mazzon E. The neuropathic pain: an overview of the current treatment and future therapeutic approaches. Int J Immunopathol Pharmacol. (2019) 33. doi: $10.1177 / 2058738419838383$
165. Fillingim RB, Bruehl S, Dworkin RH, Dworkin SF, Loeser JD, Turk DC, et al. The ACTTION-American Pain Society Pain Taxonomy (AAPT): an evidence-based and multidimensional approach to classifying chronic pain conditions. J pain. (2014) 15:241-9. doi: 10.1016/j.jpain.2014. 01.004

Conflict of Interest: The authors declare that the research was conducted in the absence of any commercial or financial relationships that could be construed as a potential conflict of interest.

Publisher's Note: All claims expressed in this article are solely those of the authors and do not necessarily represent those of their affiliated organizations, or those of the publisher, the editors and the reviewers. Any product that may be evaluated in this article, or claim that may be made by its manufacturer, is not guaranteed or endorsed by the publisher.

Copyright $\odot 2021$ Betancur, Tarragó, Torres, Fregni and Caumo. This is an openaccess article distributed under the terms of the Creative Commons Attribution License (CC BY). The use, distribution or reproduction in other forums is permitted, provided the original author(s) and the copyright owner(s) are credited and that the original publication in this journal is cited, in accordance with accepted academic practice. No use, distribution or reproduction is permitted which does not comply with these terms. 